\title{
Regulation of Intercellular Adhesion Molecule-1 (ICAM-1) in Ischemic and Reperfused Canine Myocardium
}

\author{
Gilbert L. Kukielka, * Hal K. Hawkins, ${ }^{*}$ Lloyd Michael, ${ }^{\star}$ Anthony M. Manning, * Keith Youker, * \\ Caryl Lane, * Mark L. Entman, ${ }^{\star}$ C. Wayne Smith, ${ }^{*}$ ' and Donald C. Anderson* \\ * Speros P. Martel Laboratory, Section of Leukocyte Biology, Department of Pediatrics, ”Section of Cardiovascular Sciences, \\ The Methodist Hospital and The DeBakey Heart Center, and Departments of Medicine, ${ }^{\S}$ Pathology, \\ and 'Microbiology and Immunology, Baylor College of Medicine, Houston, Texas 77030
}

\begin{abstract}
Previous studies in vitro have shown an important role for intercellular adhesion molecule-1 (ICAM-1) in adherence interactions of canine neutrophils with canine jugular vein endothelial cells and in cytotoxicity of canine neutrophils for adult cardiac myocytes. To evaluate the regulation of ICAM-1 in myocardial inflammation and its role in the pathogenesis of myocardial ischemia and reperfusion, a series of in vivo and ex vivo studies were performed in canine animals. Systemic administration of LPS elicited ICAM-1 mRNA in several tissues, including myocardium, which demonstrated increasing ICAM1 staining on intercalated discs of cardiac myocytes. In ischemia and reperfusion protocols: ( $a$ ) ICAM-1 mRNA was found in ischemic segments within $1 \mathrm{~h}$ of reperfusion and in both ischemic and normally perfused segments by $24 \mathrm{~h}$ of reperfusion; (b) expression of ICAM-1 was detected in cardiac myocytes in the ischemic region by $6 \mathrm{~h}$ of reperfusion; increased expression was seen thereafter as a function of time; $(c)$ postischemic (but not preischemic) cardiac lymph collected at intervals from 1 to $24 \mathrm{~h}$ after reperfusion elicited ICAM-1 mRNA, ICAM-1 expression, and ICAM-1-dependent neutrophil adhesion in canine jugular vein endothelial cells and in cardiac myocytes with peak cytokine activity seen by $1 \mathrm{~h} ;(d)$ extravascular localization of neutrophils was detected in ischemic areas only, and was associated with endothelium bearing high levels of ICAM-1 within $1 \mathrm{~h}$ of reperfusion; infiltration increased thereafter in association with increasing levels of ICAM-1 mRNA in myocardial segments and increasing levels of ICAM-1 expression on cardiac myocytes. These findings provide the first direct evidence for inflammatory regulation of ICAM-1 in ischemic and reperfused canine myocardium. They support the hypothesis that ICAM-1 participates in neutrophil-mediated myocardial damage. (J. Clin. Invest. 1993. 92:1504-1516.) Key words: cell adhesion molecules • myocar-
\end{abstract}

Address correspondence to Dr. Gilbert L. Kukielka, Baylor College of Medicine, Leukocyte Biology, Texas Children's Hospital, Clinical Care Center, Suite 1130, 6621 Fannin, MC 3-2372, Houston, TX 770302399.

The current address for Drs. Manning, Lane, and Anderson, is Division of Discovery Research, Upjohn Laboratories, Kalamazoo, MI 49001.

Received for publication 2 October 1992 and in revised form 22 April 1993.

J. Clin. Invest.

(c) The American Society for Clinical Investigation, Inc. $0021-9738 / 93 / 09 / 1504 / 13 \quad \$ 2.00$

Volume 92, September 1993, 1504-1516 dial infarction - myocardial ischemia and reperfusion injury • neutrophil • inflammation

\section{Introduction}

The association of inflammation with myocardial infarction has been recognized for over $50 \mathrm{yr}$ (1). Histopathologic findings in human patients have shown that neutrophils accumulate in infarcted myocardium during the first $24 \mathrm{~h}$ after onset of clinical symptoms (1). Numerous studies in experimental animals have shown that when ischemic myocardial tissue is reperfused with normally oxygenated blood, an inflammatory process ensues (2). Neutrophils accumulate preferentially in ischemic myocardial segments (3-6); this is temporally associated with the appearance of $\mathrm{C} 5 \mathrm{a}$ and other factors chemotactic for neutrophils, which are detectable in lymph draining previously ischemic myocardium (7). Experimental techniques designed to remove neutrophils from the circulation $(3,8-11)$ or to inhibit their function (2) have afforded measurable reductions in the extent of myocardial injury after ischemia and reperfusion. Such studies imply a deleterious role for neutrophil inflammatory functions in extending myocardial injury.

Several lines of evidence indicate that intercellular adhesion mechanisms are necessary for leukocyte sequestration in ischemic tissues including myocardium (12). The important contributions of $\beta 2$ integrins to this process have been shown using monoclonal antibodies administered systemically to experimental animals. Studies in canine models of cardiac ischemia/reperfusion have shown that the anti-CD11b mAb 904 significantly diminished infarct size (13-15), and the antiCD18 mAbs MHM23 (16), IB4 (17), and R15.7 (18) were each capable of reducing neutrophil accumulation, during the first $6 \mathrm{~h}$ of reperfusion. These findings are consistent with observations of Dreyer $(7,19)$, who showed that factors present in postischemic cardiac lymph stimulate the expression of CD11b/CD18 and CD18-dependent adhesion of canine neutrophils. Moreover, preliminary studies in a primate model of ischemia/reperfusion injury indicate that monoclonal antibody R6.5 directed against intercellular adhesion molecule-1 (ICAM-1), a ligand for CD18 in endothelial cells and cardiac myocytes, has a protective effect (20).

In previous in vitro studies we have shown that canine endothelial cells and cardiac myocytes express ICAM-1 in response to cytokine stimulation and that ICAM-1 functions as an adhesive molecule for neutrophils in both cell types (21-24). As shown in $\mathrm{mAb}$ inhibition protocols, transendothelial migration by neutrophils requires cooperative interactions of

1. Abbreviations used in this paper: CJVEC, canine jugular vein endothelial cells; DPBS, Dulbecco's phosphate-buffered balanced salt solution; ICAM-1, intercellular adhesion molecule-1. 
CD1 1b/CD18 and CD1 1a/CD18 with ICAM-1 (25-29). Adhesion-primed oxidative secretion by chemotactically activated canine neutrophils requires interactions of $\mathrm{CD} 1 \mathrm{lb} /$ CD18 with cytokine or LPS stimulated endothelial cells bearing high levels of ICAM-1 (30-33). Furthermore, oxidative cytotoxicity of canine neutrophils for cardiac myocytes also requires the interactions of ICAM-1 with CD11/CD18 (21, 34). Consistent with these findings, Youker et al. (23) have recently demonstrated the capacity of postischemic cardiac lymph to stimulate ICAM-1 in cultured endothelial cells and isolated cardiac myocytes.

The present studies extend previous in vitro work and were designed to directly evaluate the role of ICAM- 1 in myocardial inflammation associated with ischemia and reperfusion. In vivo and ex vivo protocols described here provide evidence that ICAM-1 synthesis is induced in myocardium of LPS-treated dogs and that ICAM-1 is elicited in ischemic myocardium in a time-dependent manner. In addition, these studies demonstrate that factors present in postischemic cardiac lymph taken at various intervals after reperfusion are capable of inducing ICAM-1 mRNA, ICAM-1 expression, and ICAM-1-dependent neutrophil adhesion in both endothelial cells and cardiac myocytes. These findings support the hypothesis that ICAM-1 plays a role in the pathogenesis of reperfusion injury of myocardium.

\section{Methods}

\section{Ischemia-reperfusion protocols}

Healthy mongrel dogs (15-25 kg) of either sex were surgically instrumented as previously described $(7,21,35,36)$. Anesthesia was induced intravenously with $10 \mathrm{mg} / \mathrm{kg}$ methohexital sodium (Brevital EL; Lilly and Co., Indianapolis, IN) and maintained with the inhalational anesthetic Isoflurane (Anaquest, Madison, WI). A midline thoracotomy provided access to the heart and mediastinum, and cannulation of the cardiac lymph duct was then performed (7). Briefly, injection of 0.05 $0.2 \mathrm{ml}$ of $0.5 \%$ Evans blue dye subepicardially into the posterolateral wall of the left ventricle allowed lymphatic vessel definition. The largest vessel was selected and cannulated at a site proximal to the cardiac lymph node and $2-5 \mathrm{~cm}$ from the base of the heart. Accessory noncardiac lymphatic vessels and tracheobronchial lymphatic connections in this region were ligated. Subsequently, a hydraulically activated occluding device and a Doppler flow probe (7) were secured around the circumflex coronary artery just proximal or just distal to the first branch. Choice of location depended on the proximity and anatomical arrangement of lymphatic vessels adjacent to the coronary vessels, so that subsequent dissection would not damage the lymphatic system. To prevent damage of lymphatic vessels in close proximity to the coronary vasculature, dissection of adipose tissue adjacent to the coronary vessel at two sequential 3-4-mm sections was carefully performed, with subsequent placement of the occluding device and flow probe. In animals selected for experimental assessments of cardiac lymph, intact lymphatic vessels draining the regions of ischemic myocardium were identified by injecting Evans blue dye $(0.05 \mathrm{ml})$ into the free wall of the left ventricle after the occluder and flow probe were in place. The appearance of Evans blue dye in the cardiac lymph cannula confirmed the patency of the lymph vessels. Indwelling cannulae, placed in the right atrium, left atrium, and femoral artery, allowed blood sampling and pressure monitoring as needed.

The animals were allowed to recover for $72 \mathrm{~h}$ before occlusion. Ischemia-reperfusion protocols were performed in awake animals as described (7). Coronary artery occlusion was achieved by inflating the coronary cuff occluder until mean flow in the coronary vessel was zero, as determined by the Doppler flow probe. At the end of $1 \mathrm{~h}$ the cuff was deflated and the myocardium was reperfused. Reperfusion intervals ranged from 1 to $24 \mathrm{~h}$. Circumflex blood flow, arterial blood pressure, heart rate, and electrocardiogram (standard limb II) were recorded continuously. Analgesia was accomplished with pentazocine ( Talwin ${ }^{\circledR}$; Winthrop Pharmaceuticals, New York, NY) $0.1-0.2 \mathrm{mg} / \mathrm{kg}$ intravenously (i.v.).

Lymph samples were collected from the cannulae in tubes containing $10 \mathrm{U}$ of preservative-free heparin. The samples were spun in a table top centrifuge at $13,000 \mathrm{~g}$ for $5 \mathrm{~min}$. Aliquots of supernatants were immediately frozen in liquid nitrogen and stored at $-80^{\circ} \mathrm{C}$ until ready to use. For all incubation protocols lymph samples, once thawed, were used immediately.

After the reperfusion periods, hearts were stopped by the infusion of saturated potassium chloride and removed from the chest for sectioning from apex to base into four transverse rings $\sim 1 \mathrm{~cm}$ in thickness. The posterior papillary muscle and the posterior free wall were identified. Tissue samples $(0.25-1.0 \mathrm{~g})$ were isolated from infarcted $(\mathrm{I})$ or normally perfused $(C)$ myocardium based on visual inspection. Frozen tissue samples were processed in a blinded fashion for RNA isolation and analysis; duplicate samples were fixed in $10 \%$ buffered formalin for histologic analysis and frozen with $\mathrm{OCT}^{\otimes}$ (Miles Inc., Elkhart, IN) in liquid nitrogen-cooled Isopentane (Fisher Scientific, Pittsburgh, PA) for immunostaining. Tissue sections fixed in $10 \%$ buffered formalin were also processed for blood flow determinations using radiolabeled microspheres as previously described $(37,38)$. For comparison of the pattern of ICAM-1 immunostaining, portions of myocardium were rapidly frozen from a transplanted human heart which was removed during an episode of acute rejection when a second cardiac transplant was performed.

\section{Neutrophil isolation}

Canine neutrophils were isolated from citrate anticoagulated venous blood using techniques previously described for the isolation of human neutrophils (39). This yielded a preparation of cells $>95 \%$ neutrophils with $>99 \%$ viability. These cells were suspended in Dulbecco's phosphate-buffered balanced salt solution (DPBS) and used within $4 \mathrm{~h}$.

\section{Isolation of cardiac myocytes}

Previously described procedures were used (21). Briefly, healthy mongrel dogs weighing $10-15 \mathrm{~kg}$ were anesthetized using sodium pentobarbital. The heart was removed through the left lateral chest under sterile conditions, and immediately placed in ice-cold saline. The aorta was then cannulated using a tubing adapter suitable for the individual heart. The adapter was then connected to a peristaltic pump and retrograde perfusion was initiated using medium A (Joklik modified minimum essential medium; Sigma Chemical Co., St. Louis, MO), containing $2 \mathrm{~g} /$ liter sodium bicarbonate, $0.1 \%$ fatty acid-free BSA, and equilibrated with $95 \% \mathrm{O}_{2} / 5 \% \mathrm{CO}_{2}$ before perfusion; perfusion was maintained several minutes until all left ventricular vessels were cleared of blood. The perfusate was then changed to medium B (medium A containing $120 \mathrm{U} / \mathrm{ml}$ collagenase type III; Worthington Biochemical Corp., Freehold, $\mathrm{NJ}$ ) and perfusion continued for $10 \mathrm{~min}$. At this point the heart was removed from the cannula and $10 \mathrm{~g}$ of left ventricle was trimmed of connective tissue then minced and placed in an Erlenmeyer flask containing $50 \mathrm{ml}$ medium $\mathrm{B}$. The flask was equilibrated with $95 \% \mathrm{O}_{2} / 5 \% \mathrm{CO}_{2}$ gas, sealed, and placed in a shaker bath at $90-100 \mathrm{cycles} / \mathrm{min}$ at $35^{\circ} \mathrm{C}$. After $20 \mathrm{~min}$ the supernatant was filtered through one layer of cheesecloth and another $50 \mathrm{ml}$ of medium B added and the procedure repeated five to six times. The cells were allowed to settle at room temperature for $\approx 5 \mathrm{~min}$ and the overlying solution was removed. The cell pellet was then suspended in medium A and the cells allowed to settle. This was then repeated and viability was measured using trypan blue dye exclusion. Preparations with a viability of $>80 \%$ were used in incubation experiments. Cells were used within $5 \mathrm{~h}$ of isolation.

Isolation of canine jugular vein endothelial cells (CJVEC)

These cells were obtained by modification of the method of Ford (25). Jugular veins were everted on glass rods and incubated in collagenase 
solution (type III, $50 \mathrm{U} / \mathrm{ml}$; Worthington Biochemical Corp.) for 10 $\min$. Cells were collected by centrifugation and suspended in DME containing $4 \%$ fetal calf serum, $4 \%$ bovine calf serum, $50 \mu \mathrm{g} / \mathrm{ml}$ endothelial cell growth factor (Collaborative Research Inc., Lexington, MA), $50 \mu \mathrm{g} / \mathrm{ml}$ heparin, $1 \mathrm{mM}$ sodium pyruvate, and antibiotics. Cells were seeded in Primaria flasks (Becton Dickinson, Lincoln Park, NJ). After 2-4 d of incubation at $37^{\circ} \mathrm{C}$ in a $\mathrm{CO}_{2}$ incubator, areas of cells with "cobble-stone" morphology were collected by scraping, transferred to gelatin-coated flasks, and grown to confluence. Second passage cells were obtained by scraping, seeded onto type I collagen-coated ( $5 \mu \mathrm{g} /$ $\mathrm{ml}$ ) 25-mm round cover glasses, and grown to confluence. Only preparations of cells where representative uniform monolayers exhibited acetylated low density lipoprotein (Dilac-LDL; Biomedical Technologies, Inc., Stoughton, MA) uptake and endothelial (cobble-stone) morphology were used in adhesion assays.

\section{Detection of $m A b$ binding to CJVEC}

For these studies, the anti-canine ICAM-1 mAb (IgG $)_{1}$ CL18/1D8 was used (24). An enzyme immunoassay to detect binding of CL18/ 1D8 to monolayers of CJVEC was performed in 96-well microliter plates as previously described (25).

\section{Immunohistochemistry and histology}

Cryostat sections $6 \mu \mathrm{m}$ thick were fixed in acetone and air dried. Sections were treated with $1 \%$ sodium metaperoxidate for $30 \mathrm{~min}, 0.1 \mathrm{M}$ ammonium chloride for $30 \mathrm{~min}$, and $1 \%$ horse serum for $15 \mathrm{~min}$, then incubated overnight at $4^{\circ} \mathrm{C}$ with monoclonal antibodies directed at ICAM-1 (CL18/1D8 or CL18/6, 0.01-20 $\mu \mathrm{g} / \mathrm{ml}$ ) or CD18 (R15.7, $1-10 \mu \mathrm{g} / \mathrm{ml}$ ). Antibody binding sites were visualized using an avidinbiotin-peroxidase complex immunoperoxidase technique (Vector Laboratories, Burlingame, $\mathrm{CA}$ ) using diaminobenzidine and intensifying the reaction product by brief immersion in $1 \%$ osmium tetroxide. Controls included omission of primary antibody or biotinylated link reagent and substitution of an isotype-matched nonbinding monoclonal antibody. To estimate the relative levels of ICAM-1 on endothelia of various vessel types, frozen sections were immunostained using a wide range of concentrations of mAb. For most studies in this report, CL18/ 1D8 mAb was used because it demonstrated less background staining than $\mathrm{CL} 18 / 6$, although similar patterns of staining of endothelial cells and myocytes were seen with both of these monoclonal antibodies. For combined staining of CD18 on neutrophils and ICAM-1 on endothelium and myocytes, mAbs R15.7 and CL18/1D8 were mixed together during the overnight incubation step. For immunostaining of human ICAM-1, mAb R6.5 was used at $0.5 \mu \mathrm{g} / \mathrm{ml}$. For histologic study of cardiac tissue, sections taken from endocardium to epicardium and sections taken parallel to the wall of the heart were fixed in $10 \%$ phosphate-buffered formalin, embedded in paraffin, sectioned, and stained with hematoxylin and eosin.

\section{Antibodies}

The anti-CD18 mAb R15.7 (IgG1) (21) and the anti-human ICAM-1 mAb R6.5 (IgG1) (40) were supplied by Dr. Robert Rothlein (Boehringer-Ingelheim Pharmaceuticals, Inc., Ridgefield, CT). The anticanine ICAM-1 mAbs CL18/6 (IgG1) and CL18-1D8 (IgG1) were prepared as described elsewhere (24).

\section{Adhesion assays}

Canine neutrophil adherence to CJVEC monolayers. Confluent monolayers of CJVEC on glass coverslips were inserted into adhesion chambers, and the adhesion of isolated canine neutrophils was visually determined under static conditions as previously described $(24,25)$. In experiments with stimulated endothelial cells, monolayers were preincubated with rTNF $\alpha$ (Boehringer-Ingelheim Pharmaceuticals, Inc.) or cardiac lymph for $3 \mathrm{~h}$ at $37^{\circ} \mathrm{C}$, then rinsed by dipping coverslips five times in two changes of DPBS before inserted into adherence chambers. In experiments with mAb CL18/6 (an antibody that blocks the function of canine ICAM-1) (24), monolayers were preincubated with the $\mathrm{mAb}(10 \mu \mathrm{g} / \mathrm{ml})$ at room temperature for $5 \mathrm{~min}$ before rinsing in DPBS.

Canine neutrophil-myocyte adhesion. Isolated myocytes were suspended in medium $A$ at a concentration of $50,000 / \mathrm{ml}$ as previously described (21). These cells were preincubated in DPBS, TNF $\alpha$, or cardiac lymph for $2-8 \mathrm{~h}$ at $37^{\circ} \mathrm{C}$ before use in adhesion assays. Isolated canine neutrophils were prestimulated with $1 \%$ zymosan-activated serum (zymosan was purchased from Sigma Chemical Co., prepared as described [7]) before use in adhesion assays. Neutrophils and myocytes were coincubated in a volume of $0.4 \mathrm{ml}$ at a neutrophil/myocyte ratio of $10: 1$, for the last $60 \mathrm{~min}$ at $37^{\circ} \mathrm{C}$. The cells were transferred to a microscope slide for examination. For each suspension, the numbers of neutrophils adherent to each of 200 myocytes was counted in a blinded fashion. In experiments with CL18 mAb, myocytes were preincubated with the $\mathrm{mAb}(40 \mu \mathrm{g} / \mathrm{ml})$ for $5 \mathrm{~min}$ before incubation with neutrophils.

Preparation of canine ICAM-1 CDNA. Canine spleen CDNA was amplified using PCR and degenerate oligonucleotide primer mixtures corresponding to highly conserved sequences of murine and human ICAM-1 cDNA as previously described in detail (24). Aliquots of PCR reactions were analyzed on $1 \%$ agarose gels followed by Southern blotting and hybridization with murine or human CDNA probes for ICAM1 labeled by the random hexamer method (41). A product of $740 \mathrm{bp}$ was observed by ethidium staining and by hybridization with both canine and murine PCR products. This canine PCR product was cloned into M13mp18(42) and when sequenced, demonstrated homology to human ICAM-1 (60.9\% amino acid identity) and murine ICAM-1 (53\% amino acid identity) within Ig domains II-V (24).

Northern blot and slot blot analyses. RNA was isolated from cultured CJVEC, isolated canine myocytes, or myocardial tissue segments using the acid guanidinium phenol chloroform procedure (43). For Northern blots, RNA (10-20 $\mu \mathrm{g}$ ) was electrophoresed in $1 \%$ agarose gels containing formaldehyde, then transferred to a nylon membrane (Gene Screen Plus; New England Nuclear, Boston, MA) by standard procedures (44). For slot blot analyses RNA (2.5-10 $\mu \mathrm{g})$ was transferred to nylon membranes in a slot blot apparatus (Schleicher and Schuell, Keene, NH) under negative pressure. Membranes were hybridized in $50 \%$ formaldehyde, $10 \%$ dextran sulfate, $1 \% \mathrm{SDS}, 96 \mathrm{~mm} \mathrm{NaCl}$, $0.15 \mathrm{mg} / \mathrm{ml}$ salmon sperm DNA, and $1 \times 10^{6}$ disintegrations per minute of random hexamer ${ }^{32} \mathrm{P}$-labeled canine ICAM-1 cDNA probe for every milliliter of hybridization solution. Filters were washed with 2 $\times$ SSC at $21^{\circ} \mathrm{C}$ for 5 min twice, with $2 \times$ SSC with $1 \%$ SDS at $65^{\circ} \mathrm{C}$ for 30 min twice, and were then exposed to Kodak XAR film (Eastman Kodak Co., Rochester, NY).

\section{Results}

Induction of ICAM-1 $\mathrm{mRNA}$ in canine tissues. Regulation of ICAM-1 mRNA in vivo was initially studied in animals after systemic administration of LPS and in untreated control animals. After $3 \mathrm{~h}$ of LPS ( $1 \mathrm{mg} / \mathrm{kg}$ ) administration, tissues were removed at autopsy and immediately frozen for Northern blot (Fig. $1 a$ ), slot blot (Fig. $1 b$ ), and immunostaining (Fig. 1 c) analyses. Induction of ICAM-1 mRNA was observed in all tissues examined, but was particularly strong in spleen, lung, kidney, and liver. In addition to a dominant hybridizing band of $2.9 \mathrm{~kb}$, a lower molecular weight band of $\approx 1.9 \mathrm{~kb}$ was evident in some tissues, similar to that previously demonstrated in LPS or cytokine-stimulated CJVEC in vitro (24). As illustrated in unstimulated lung and spleen in Fig. $1 a$, ICAM-1 mRNA was not detected in tissues of control animals. The induction of ICAM- 1 mRNA by LPS was also examined in a semiquantitative fashion in slot blots. The highest levels of ICAM-1 mRNA were demonstrated in spleen, lung, and kidney, whereas lower but clearly detectable signals were evident in thymus and liver, as well as myocardium (Fig. $1 \mathrm{~b}$ ). Immunostaining protocols 


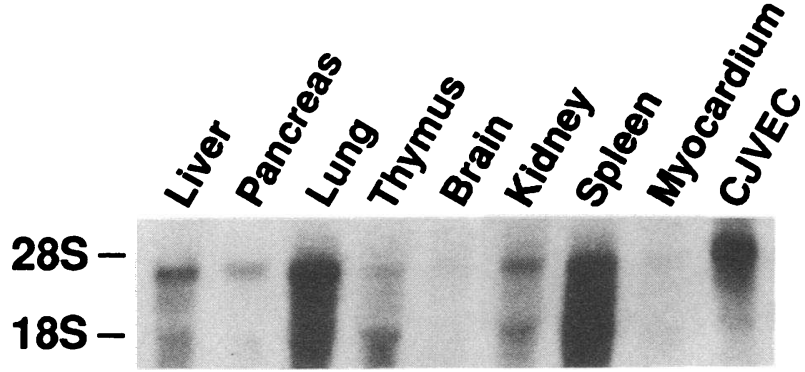

a LPS Stimulated

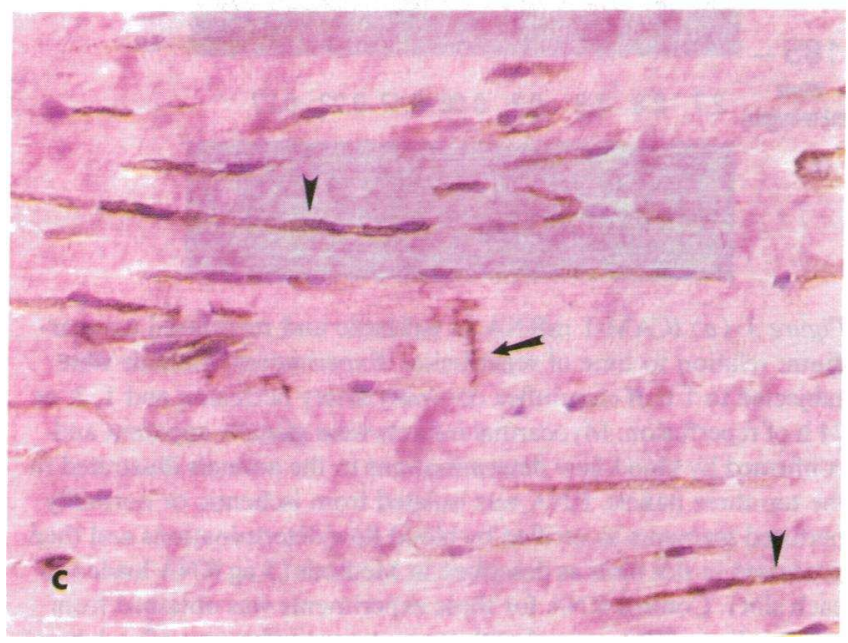

in the same animals confirmed the induction of ICAM-1 protein in myocardium. This was shown by intense focal staining of the CL18/1D8 mAb of intercalated discs of cardiac myocytes of LPS-treated animals (Fig. $1 c$ ). Although the distribution and intensity of endothelial ICAM-1 was similar among LPS-treated and control animals, no CL18 / 1 D8 mAb staining of cardiac myocytes was evident in myocardial segments of control animals (not shown).

Induction of ICAM-1 MRNA in ischemic and reperfused myocardium. To characterize the regulation of ICAM-1 mRNA in ischemic and reperfused myocardium, circumflex coronary artery occlusion and reperfusion experiments were performed. Representative experiments in two animals subjected to $1 \mathrm{~h}$ of coronary occlusion and $3 \mathrm{~h}$ of reperfusion are shown in Fig. 2. In the experiment illustrated on the left panel (lanes 1-4), the animal sustained a large infarct as observed visually and as confirmed by blood flow determinations. Strong signals for ICAM-1 mRNA in ischemic myocardial tissue segments of this animal were observed. Signals were most evident in segments demonstrating the lowest levels of blood flow, whereas ICAM-1 mRNA was not detectable in normally perfused anterior ventricular wall segments even after $3 \mathrm{~h}$ of reperfusion. Contrasting findings were evident in the animal illustrated on the right panel of Fig. 2 (lanes 7-10), which demonstrated no macroscopic evidence of infarction after the occlusion and reperfusion protocols. Subsequent myocardial blood flow determinations in this animal demonstrated only a

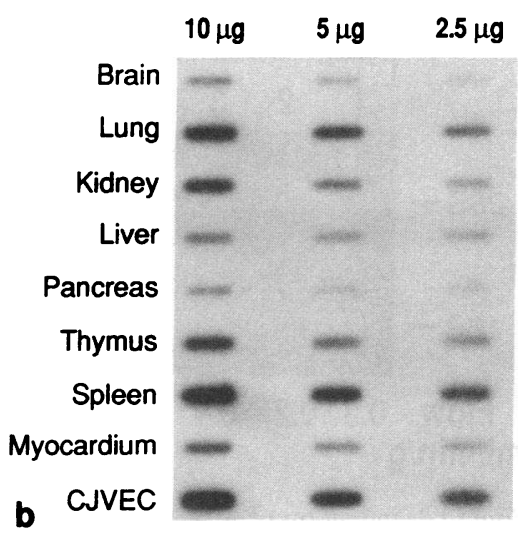

Figure 1. Induction of ICAM-1 mRNA in canine tissues. RNA was isolated from tissues of untreated control animals or from animals $3 \mathrm{~h}$ after intravenous administration of LPS $(1 \mathrm{mg} / \mathrm{kg})$ and processed in Northern blots $(a)$ or slot blots $(b)$ as described in Methods. Relative levels of ICAM-1 mRNA in tissues of untreated or LPS-treated animals are demonstrated and compared to levels elicited by LPS ( 10 $\mathrm{ng} / \mathrm{ml}, 3 \mathrm{~h}$ ) in CJVEC in vitro. For Northern blots, $15 \mu \mathrm{g}$ of RNA was loaded in each lane. $(c)$ Expression of ICAM-1 protein in canine myocardium. Myocardial tissue from an animal systemically administered LPS ( $1 \mathrm{mg} / \mathrm{kg}$ i.v.) $3 \mathrm{~h}$ earlier. Cryostat sections were immunostained as described in Methods, using the anti-canine ICAM-1 $\mathrm{mAb}$ CL18/1D8 at $10 \mu \mathrm{g} / \mathrm{ml}$. In addition to the endothelium of small blood vessels including capillaries (arrowheads), intercalated discs joining adjacent myocytes also contain brown reaction product (arrows). Staining of myocytes was not observed in myocardium of control animals. $\times 1,325$.

slight reduction in perfusion despite coronary artery occlusion. In this animal, ICAM-1 mRNA was detected in normally perfused myocardial segments (Fig. 2, lanes 7 and 8). ICAM-1 mRNA was detected in segments with diminished levels of blood flow (Fig. 2, lanes 9 and 10), but was less intense than observed with more severe blood flow reductions. As shown, these ICAM-1 mRNA levels were comparable to those observed in myocardium of LPS-treated animals (lane 6 ) and to the high levels elicited by LPS ( $\left.10 \mathrm{ng} / \mathrm{ml}, 37^{\circ} \mathrm{C}, 3 \mathrm{~h}\right)$ in cultured CJVEC (lane 5).

Regulation of ICAM-1 $\mathrm{mRNA}$ in ischemic and reperfused myocardium: relationship to time of reperfusion and blood flow. To evaluate the relationship of time and induction of ICAM-1 in ischemic myocardium, a series of coronary artery occlusion and reperfusion protocols were carried out. Experimental animals were subjected to $1 \mathrm{~h}$ of occlusion followed by 1,3 , or $24 \mathrm{~h}$ of reperfusion. Large myocardial infarcts were apparent in the three animals illustrated in the top three panels of Fig. $3 a$. Time-dependent induction of ICAM-1 mRNA was observed in ischemic segments analyzed among each of these animals. Enhanced expression was most evident in $24 \mathrm{~h}$ reperfusion segments which showed tenfold increases over 1-h ischemic segments. ICAM-1 mRNA was not detected in normally perfused segments of animals reperfused for 1 or $3 \mathrm{~h}$. However, in 24-h reperfusion protocols, normally perfused segments consistently demonstrated enhanced levels of ICAM-1 mRNA comparable to those seen in ischemic segments of the same animals 


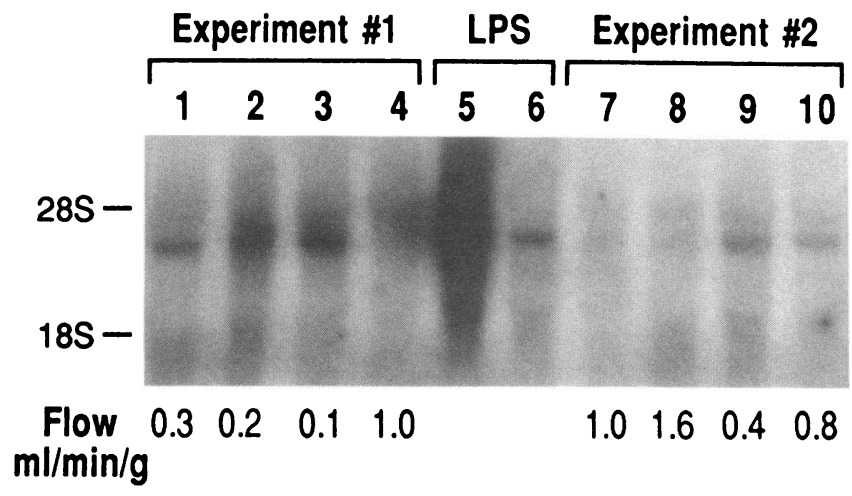

Figure 2. Induction of ICAM-1 mRNA in ischemic and reperfused canine myocardium. Representative experiments are shown in two canine animals subjected to $1 \mathrm{~h}$ of coronary artery occlusion followed by $3 \mathrm{~h}$ of reperfusion. A myocardial infarct was visually apparent in the animal shown in the left panel (lanes 1-4), whereas no infarct was macroscopically observed in the second animal shown in the right panel (lanes 7-10). Tissue segments were isolated from infarcted posterior papillary muscle or normally perfused anterior wall myocardium of the first animal. Normally perfused myocardium from the anterior wall or segments within the circumflex artery distribution were isolated from the second animal. RNA was isolated from each segment and processed in Northern blots in a blinded fashion ( $15 \mu \mathrm{g}$ total cell RNA loaded per lane). Duplicate samples were processed for blood flow determinations using radiolabeled microspheres as described in Methods. Levels of ICAM-1 mRNA in myocardial segments are compared to those elicited in CJVEC by LPS $(10 \mathrm{ng} / \mathrm{ml}, 3$ h) in vitro or myocardium of an animal administered LPS ( $1 \mathrm{mg} / \mathrm{kg}$ i.v.; $3 \mathrm{~h}$ ). Designated lanes are as follows: 1,2 , and 3 , infarcted posterior papillary muscle segments; 4 , normally perfused anterior myocardial wall; 5, LPS-stimulated CJVEC; 6 , myocardium of LPStreated animal; 7, normally perfused anterior myocardial wall; 8,9 , and 10 , myocardial segments within the circumflex artery distribution of the second animal. Blood flow determinations are indicated for each myocardial segment assessed in ischemia-reperfusion (I/R) protocols. $28 \mathrm{~S}$ and $18 \mathrm{~S}$ markers are at $4.4 \mathrm{~kb}$ and $2.0 \mathrm{~kb}$, respectively.

and in myocardium of LPS-treated animals (Fig. 3, $a$ and $b$ ). Only minimal induction of ICAM-1 mRNA was observed in myocardial segments of an additional animal with no evidence of infarction despite $1 \mathrm{~h}$ of coronary artery occlusion.

These relationships are graphically summarized in Fig. $4 a$, where densitometric determinations of mRNA levels were computed for myocardial segments of all test animals. As shown, ICAM-1 mRNA levels observed in myocardial segments were directly related to time of reperfusion and inversely related to regional blood flow. Even normally perfused segments (left panel) demonstrated increasing levels of ICAM-1 mRNA over time, but at each time interval, levels of ICAM-1 mRNA were elevated in ischemic as compared to nonischemic segments.

In addition to the findings of increasing ICAM-1 mRNA levels with time of reperfusion, an inverse quantitative relationship between ICAM-1 mRNA induction and regional blood flow during the ischemic period was also observed. The results from four separate experiments in which RNA was isolated from cardiac segments after $3 \mathrm{~h}$ of reperfusion are shown in Fig. $4 b$. In each experiment, blood flow values for several control segments were determined and averaged to compute " $100 \%$ blood flow" values. The figure demonstrates the absence of ICAM-1 mRNA in control (100\% blood flow) seg-
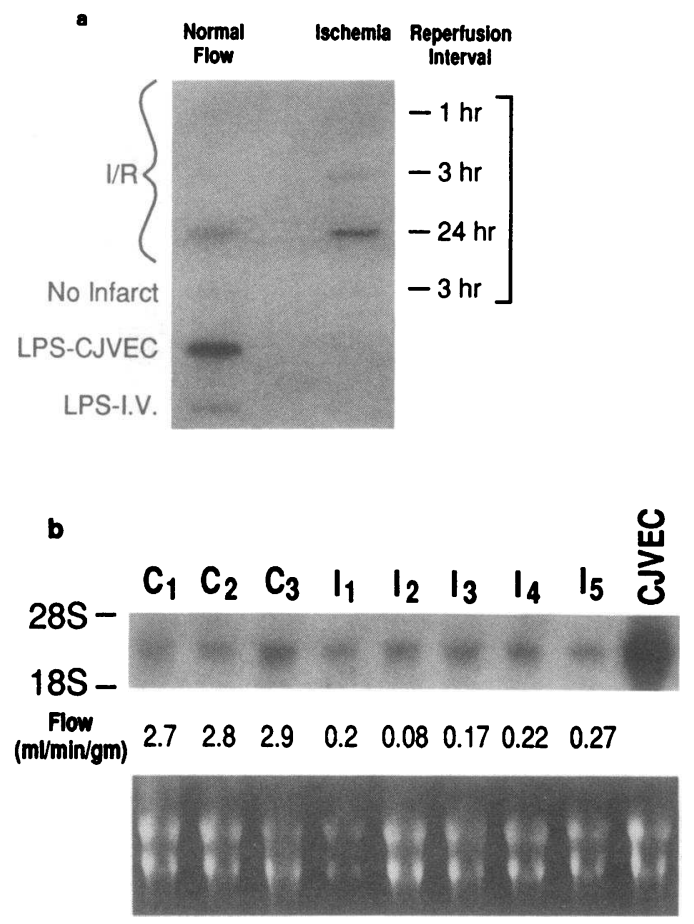

Figure 3. (a) ICAM-1 mRNA in ischemic and reperfused myocardium: relation to time of reperfusion. Experimental animals were subjected to $1 \mathrm{~h}$ of circumflex coronary artery occlusion and 1,3 , or $24 \mathrm{~h}$ of reperfusion. Myocardial infarcts were visually apparent and confirmed by blood flow determinations in the animals illustrated in the top three panels. RNA was isolated from ischemic or normally perfused segments as verified by blood flow determinations and then processed in slot blots as described in Methods ( $5 \mu \mathrm{g}$ RNA loaded in each slot). Control RNA for these experiments was obtained from myocardium of an animal with no apparent infarction after $1 \mathrm{~h} \mathrm{oc-}$ clusion and $3 \mathrm{~h}$ of reperfusion, CJVEC stimulated with LPS ( $10 \mathrm{ng}$ / $\mathrm{ml}, 3 \mathrm{~h}$ ) and from myocardium of an animal pretreated with LPS (1 $\mathrm{mg} / \mathrm{kg}, 3 \mathrm{~h}$, i.v.). (b) ICAM-1 mRNA in ischemic and reperfused canine myocardium after $24 \mathrm{~h}$ of reperfusion. Experimental animals were subjected to $1 \mathrm{~h}$ of coronary occlusion and $24 \mathrm{~h}$ of reperfusion. RNA was isolated from ischemic or normally perfused segments. Duplicate segments were processed for blood flow determinations using radiolabeled microspheres as indicated. $12 \mu \mathrm{g}$ was loaded in each lane shown by ethidium bromide staining ( bottom panel). Relative levels of ICAM-1 mRNA in control (lanes $C$ ) and ischemic (lanes $I$ ) segments are demonstrated and compared to levels elicited by rTNF $\alpha$ $(30 \mathrm{U} / \mathrm{ml}, 3 \mathrm{~h})$ in CJVEC. Upper panel represents Northern blot as described; lower panel is ethidum bromide staining.

ments, and substantially higher levels of ICAM-1 mRNA in segments in which coronary blood flow was reduced by $50 \%$ or more. Generally, mRNA determinations increased as an inverse function of coronary blood flow during ischemia.

Immunostaining of ICAM-1 in ischemic and control myocardial segments. The expression of ICAM-1 on vascular endothelium and cardiac myocytes was assessed in the same experimental animals using the mAb CL18/1D8 for immunostaining of myocardial sections. Expression of ICAM-1 was observed on capillary, venous, and arterial endothelium of all myocardial segments of all experimental animals, and in cardiac tissue of normal dogs not exposed to any surgical procedures. When tissue samples were immunostained using a wide range of concentrations of mAb CL18/1D8, venous and arterial endothelium generally demonstrated staining reactions at 

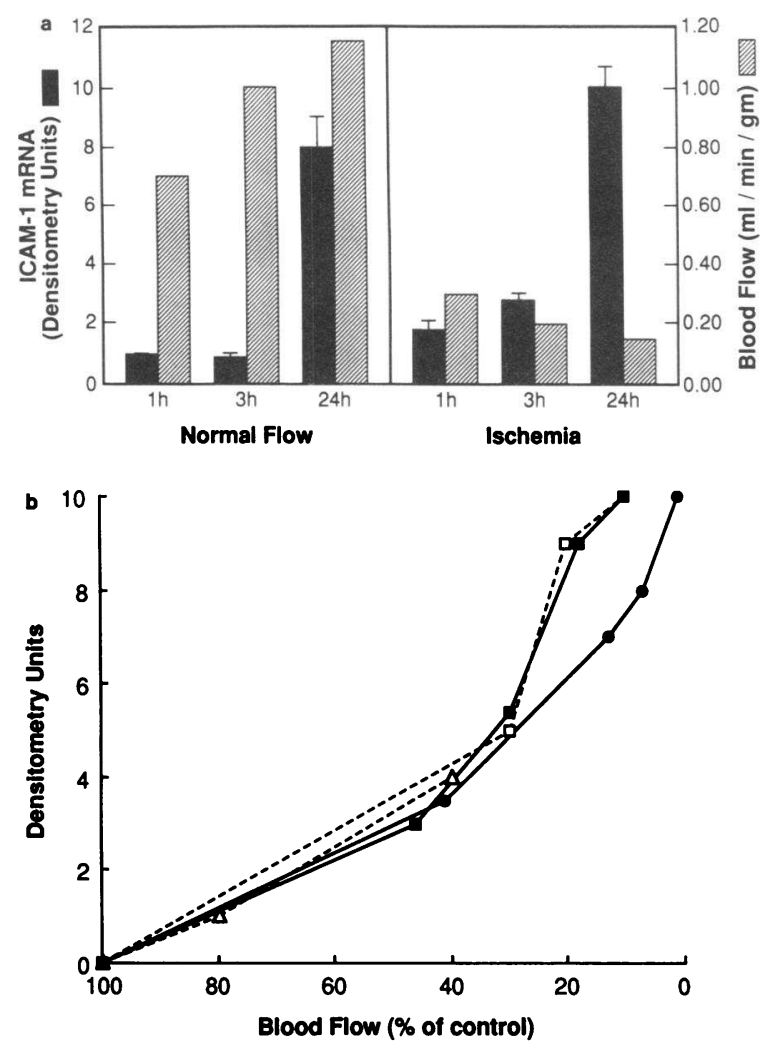

Figure 4. (a) Regulation of ICAM-1 in ischemic canine myocardium; relation to blood flow and to time of reperfusion. Experimental animals were subjected to $1 \mathrm{~h}$ of coronary occlusion and then 1,3 , or 24 $\mathrm{h}$ of reperfusion. Blood flow $(\mathrm{ml} / \mathrm{min}$ per $\mathrm{g})$ to each of the segments analyzed is shown by the cross-hatched bars, and mRNA levels determined by laser densitometry are designated by the solid bars. Data are presented for normally perfused segments (left) or ischemic segments ( right) of five test animals. Data shown represent the mean value for assessments of three to five segments for each experimental condition. Data are presented \pm 1 SD. $(b)$ Relation of ICAM-1 mRNA levels to regional blood flow in ischemic canine myocardium. Four separate animals were subjected to $1 \mathrm{~h}$ of ischemia and $3 \mathrm{~h}$ of reperfusion. RNA was isolated from ischemic and normally perfused segments and probed with ${ }^{32} \mathrm{P}$-labeled canine ICAM-1 cDNA. Densitometric values for each test segment were determined (scale of 0-10) and are expressed as a function of myocardial blood flow (percentage of control) in the same segments. Control blood flow values were computed as the mean of at least two determinations in normally perfused segments for each experiment. Blood flow in the nonischemic segments did not exceed $1.5 \mathrm{ml} / \mathrm{min}$ per g. Experiment $1, \bullet ; 2$, $\square$; $3, \Delta ; 4, \mathbf{m}$.

concentrations of primary antibody lower than those required to stain capillary and venular endothelium. Staining of endothelium was consistent and uniform at $20 \mu \mathrm{g} / \mathrm{ml}$ but became fainter and somewhat patchy below $10 \mu \mathrm{g} / \mathrm{ml}$. No differences could be detected in the intensity of endothelial ICAM-1 staining of a given vessel type when comparing control to ischemic and reperfused tissue segments, regardless of the concentration of primary antibody used. However, the intensity of endothelial staining for ICAM-1 was generally reduced in regions of necrosis (Fig. 5).

Expression of ICAM-1 on cardiac myocytes was also demonstrated in selected ischemia-reperfusion protocols (Fig. 5). As with the LPS experiments in Fig. 1, expression of ICAM-1 associated with the cardiac myocytes was detected only on in- tercalated discs. Staining was limited to small foci of myocytes which were often concentrated adjacent to necrotic areas, but were also scattered in other areas of myocardium. Myocyte ICAM-1 staining was not detected in untreated (control) animals or after 1,2 , or $3 \mathrm{~h}$ of reperfusion. In ischemic animals reperfused for $6 \mathrm{~h}$, small foci of ICAM-1 staining were evident in the ischemic area. Prominent multifocal staining of intercalated discs was consistently seen in myocardium of animals subjected to $1 \mathrm{~h}$ of ischemia and 24 or $48 \mathrm{~h}$ of reperfusion. In addition, focal staining of ICAM-1 was also seen in normally perfused tissue segments (verified by microsphere flow techniques), in some specimens from animals reperfused for 24 or $48 \mathrm{~h}$. A similar pattern of ICAM-1 immunoreactivity was seen in a section of human myocardium taken from a acutely rejected heterograft (Fig. $5 \mathrm{H}$ ).

Neutrophil accumulation after ischemia and reperfusion. Concurrent assessments of neutrophil distribution in myocardial sections were performed in the same animals, using histologic analysis and histochemical staining for neutrophils with the anti-CD18 mAb R15.7. Neither intravascular nor extravascular neutrophils were evident in sections from control (nor$\mathrm{mal}$ ) animals or in normally perfused segment of canine myocardium from animals that underwent coronary occlusion. In ischemic segments, intense accumulation of neutrophils on the luminal surface of the venous endothelium and initial neutrophil transmigration was apparent after $1 \mathrm{~h}$ of reperfusion (Fig. 6). Generally, the numbers of extravascular neutrophils in ischemic myocardium increased as a function of time of reperfusion, beginning $\sim 1 \mathrm{~h}$ of reperfusion, although substantially greater numbers of extravascular neutrophils were not apparent after more than $3 \mathrm{~h}$ of reperfusion. Infiltrating neutrophils were often concentrated in ischemic regions in the vicinity of veins which showed endothelial staining for ICAM-1 when using antibody concentrations too low to stain ICAM- 1 on capillary endothelium. Thus these studies indicate that early in reperfusion, neutrophil emigration occurs in ischemic myocardium concurrent with the induction of ICAM-1 mRNA but before detectable increases in ICAM-1 expression on cardiac myocytes. At later time intervals where ICAM-1 staining on myocytes was observed (6-24 h of reperfusion), neutrophil emigration occurred in association with increasing levels of stainable ICAM-1 on cardiac myocytes in the ischemic areas (Fig. 6). No neutrophils were observed in control areas which, at $24 \mathrm{~h}$, showed focal ICAM-1 staining on myocytes.

Stimulation of ICAM-1 in CJVEC by postischemic cardiac lymph. The capacity of cardiac lymph to stimulate ICAM-1 in CJVEC was concurrently studied in Northern blots, enzyme immunoassay, and adhesion assays as shown in Fig. 7. Whereas recombinant TNF $\alpha$ (positive control) elicited ICAM$1 \mathrm{mRNA}$, surface protein, as well as total and ICAM-1-dependent adhesion for neutrophils, no stimulatory activity was seen in preischemic lymph samples. In contrast, stimulatory activity was evident in all postischemic lymph samples when tested in each assay. As shown in Fig. 8, stimulatory activity was maximal in lymph collected during the first hour of reperfusion.

Stimulation of ICAM-1 in canine cardiac myocytes by postischemic cardiac lymph. Postischemic cardiac lymph samples taken in the first, third, and 24th hour of reperfusion were incubated with canine cardiac myocytes (Fig. 9) as previously described (23). When compared to cells exposed to preischemic samples, there was a marked increase in ICAM-1 mRNA in myocytes incubated with postischemic lymph (Fig. 9). Stim- 

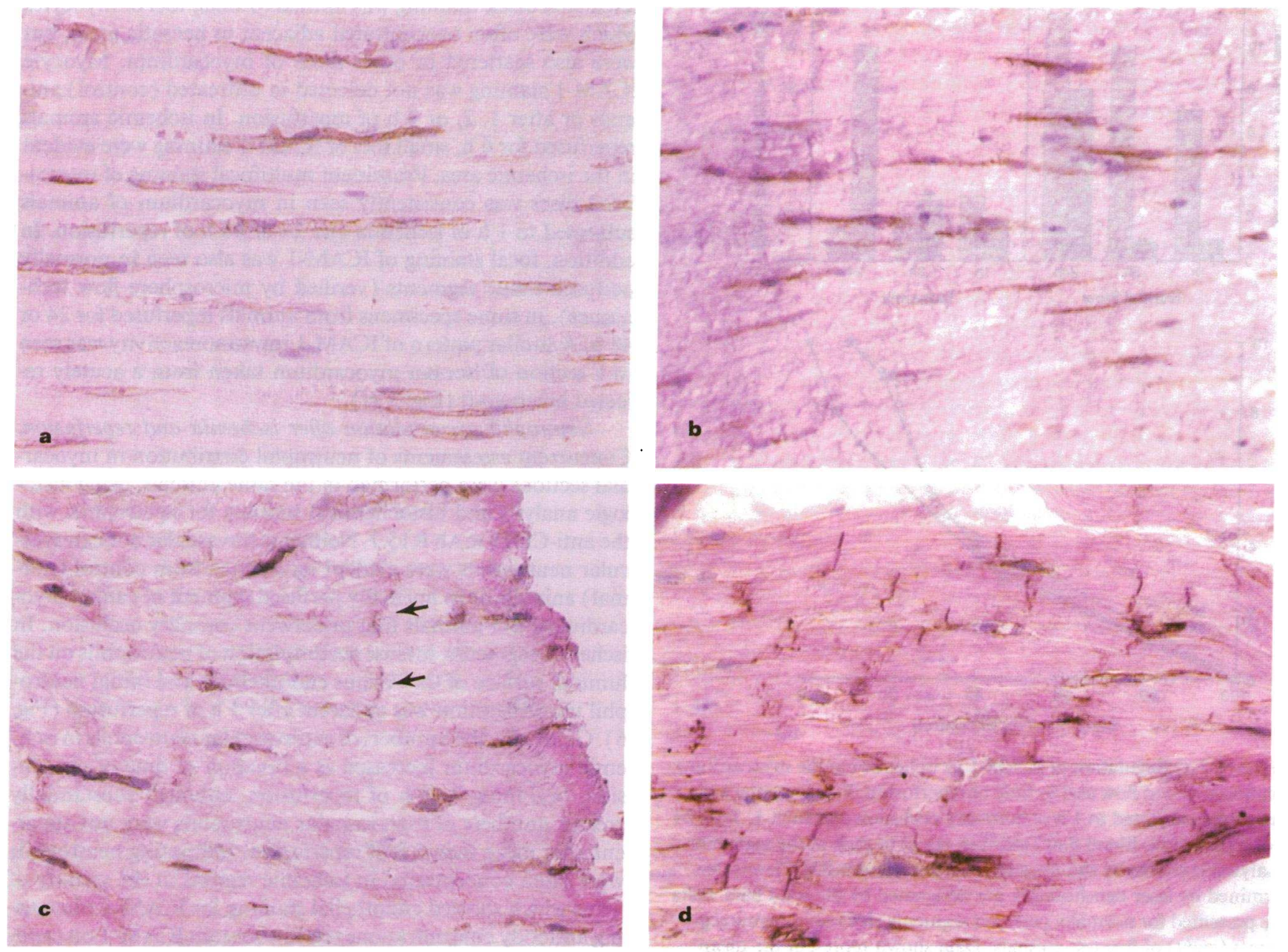

Figure 5. Distribution of ICAM-1 protein in ischemic canine myocardium. Cryostat sections of heart muscle were immunostained using mAb $\mathrm{CL18} / 1 \mathrm{D} 8$ ( 10 or $20 \mu \mathrm{g} / \mathrm{ml}$ ) and an avidin-biotin complex peroxidase reaction with diaminobenzidine and $\mathrm{OsO}_{4}$ intensification, as described in Methods. $\times 530$. ( $a$ ) Control tissue not exposed to ischemia. The endothelium of all blood vessels including capillaries labels with a dark brown reaction product indicating the presence of ICAM-1 protein. Controls, including omission of primary antibody and substitution of isotypematched nonbinding antibody, showed no staining. $(b)$ Injured but not necrotic myocardium after ischemia due to coronary artery occlusion for $1 \mathrm{~h}$ and reperfusion for $3 \mathrm{~h}$. The immunoreaction for ICAM-1 is restricted to endothelium, as in control tissue segments. (c) Injured myocardium after $1 \mathrm{~h}$ of ischemia and $6 \mathrm{~h}$ of reperfusion. In addition to endothelial cells, the immunoreaction also labels intercalated discs of cardiac myocytes focally in some animals (arrows). (d) Injured myocardium after $1 \mathrm{~h}$ of ischemia and $24 \mathrm{~h}$ of reperfusion. Intercalated discs show intense immunostaining for ICAM-1. This pattern of staining was seen in all animals but was focal. Capillary endothelial cells are also intensely labeled. (e) A cross-section of the tissue shown in $d$, affected by ischemia for $1 \mathrm{~h}$ and reperfusion for $24 \mathrm{~h}$. Intense staining of each capillary is shown. Note that no reaction product is seen on the sarcolemma bordering each myocyte (arrows). $(f)$ Necrotic tissue from the center of the infarct produced by $1 \mathrm{~h}$ circumflex coronary occlusion and $24 \mathrm{~h}$ of reperfusion. Contraction bands are visible in some cells. Much less immunostaining for ICAM-1 is seen in the necrotic tissue as compared with the adjacent injured but viable tissue. $(g)$ Control tissue not injured by ischemia, from an animal $24 \mathrm{~h}$ after $1 \mathrm{~h}$ of circumflex occlusion. Focal immunostaining is seen in the intercalated discs of adjacent myocytes. (h) Human myocardium from a heart removed after transplantation during acute allograft rejection. ICAM-1 is labeled using mAb R6.5. In addition to vascular endothelium, intercalated discs between myocytes are intensely labeled (arrows).

ulatory activity peaked in samples collected during the first hour of reperfusion. These findings are similar to the reactivity described for CVJEC in Fig. 7. ICAM-1-dependent myocyte adhesion for neutrophils was stimulated by postischemic (but not preischemic) cardiac lymph collected during reperfusion (Fig. 9). This finding was further emphasized by studies shown in Fig. 10, where neutrophil adhesion was evaluated at various time intervals (up to $8 \mathrm{~h}$ ) after myocytes were incubated in postischemic lymph. As shown, significant ICAM-1-dependent neutrophil adhesion was demonstrated by 2 h (30 min incubation, $30 \mathrm{~min}$ wash, $1 \mathrm{~h}$ neutrophil exposure) and it con- tinued to increase with longer incubation intervals. Similar experiments with preischemic lymph failed to induce neutrophil-myocyte adhesion (Fig. 10).

\section{Discussion}

These studies provide direct evidence for regulation of ICAM-1 in canine myocardium in vivo after experimental ischemia and reperfusion, and they extend our previous observations in vitro implicating an important role for ICAM-1 in myocardial injury. We have shown that ICAM-1 mRNA is increased in isch- 

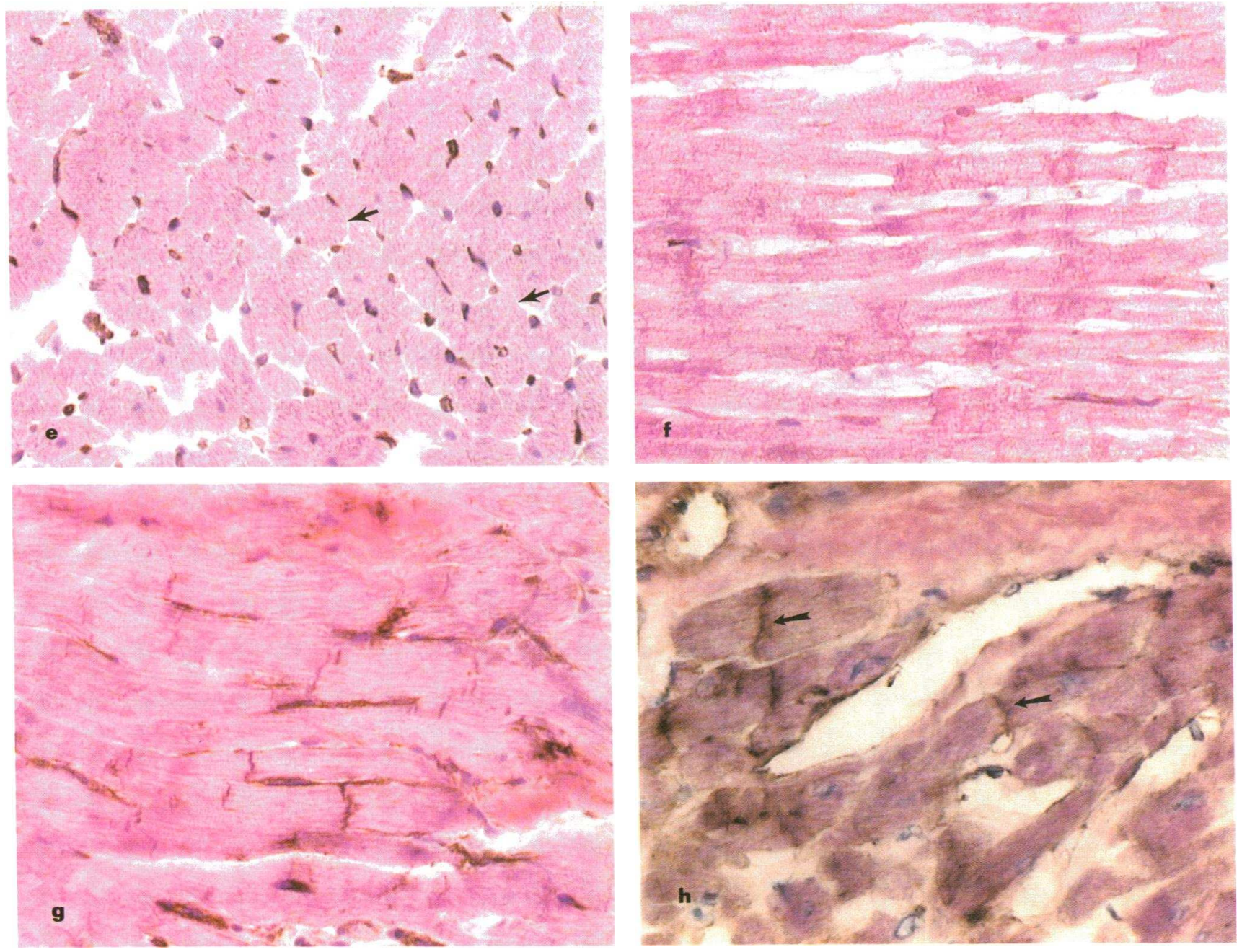

Figure 5 (Continued)

emic myocardial segments as early as $1 \mathrm{~h}$ after reperfusion, and is markedly elevated after longer time intervals. ICAM-1 protein was detected immunohistochemically on cardiac myocytes of ischemic segments by $6 \mathrm{~h}$ of reperfusion and was consistently seen after $24 \mathrm{~h}$ of reperfusion. Since it was not possible to document in ischemic and reperfused segments elevated levels of endothelial ICAM-1 above those constitutively expressed on endothelial cells of control myocardium, the apparent basis for increased levels of ICAM-1 mRNA in reperfused myocardium could be new synthesis in cardiac myocytes. However, since postischemic cardiac lymph stimulated the expression of ICAM-1 on the surface of cultured endothelium, it is likely that this would also occur in vivo. Our previous work clearly documents significant elevations of IL-6 activity in postischemic cardiac lymph shortly after reperfusion begins; a neutralizing antibody to IL-6 completely removes the ICAM-1-stimulating activity of postischemic cardiac lymph for cardiac myocytes (23). Additionally, we have shown that cardiac myocytes respond to IL- 6 by synthesizing and expressing ICAM-1 on the cell surface. In contrast to ischemic segments, ICAM-1 mRNA was not observed in normally perfused myocardial segments until $24 \mathrm{~h}$ after reperfusion. This latter finding may reflect the local release of cytokines into the systemic circulation and the subsequent induction of ICAM-1 in normal tissues. In support of this idea is the fact that IL-6-like activity was previously found to persist in cardiac lymph for up to $72 \mathrm{~h}$ after coronary artery occlusion and reperfusion (23).

The distribution of ICAM-1 induced on myocytes was unexpected. It apparently localized to intercalated discs of cardiac myocytes as verified by comparisons of longitudinal and transverse tissue sections, and contrasts with both the generalized distribution of ICAM- 1 on isolated cardiac myocytes in vitro and the capacity of canine neutrophils to randomly bind to isolated cardiac myocytes when preincubated with cytokines or LPS $(21,24)$. ICAM-1 was also observed in the intercalated discs of human myocytes in sections of myocardium after acute allograft rejection. This observation has been recently described in acutely rejected hearts by others as well (45). Localization of ICAM-1 exclusively to the intercalated disc region remains tentative since it depends upon an immunostaining reaction highly sensitive to denaturation, and the basis for this apparent distribution in vivo is not clear. Since acute allograft rejection has previously been linked to an increase in soluble ICAM-1 (46), it is possible that the distribution of ICAM-1 is influenced by cleavage of the molecule. A recent paper describes such cleavage of ICAM-1 associated with inflammatory mediators (47).

Postischemic cardiac lymph, in contrast to lymph collected before coronary occlusion, stimulated both endothelial cells and isolated myocytes in vitro to express ICAM-1 and thereby 

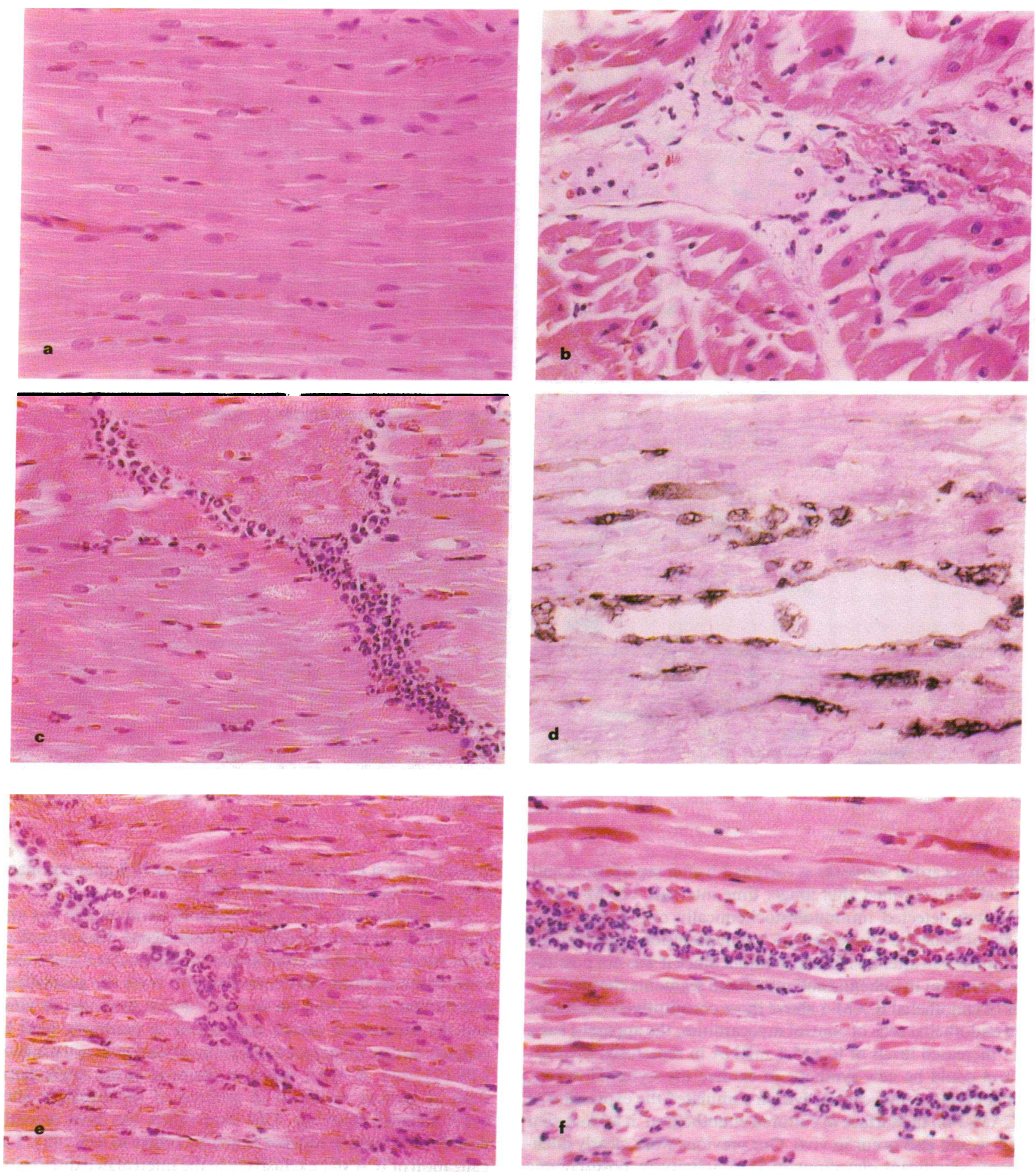

Figure 6. Infiltration of neutrophils in ischemic or reperfused myocardium. Sections of paraffin-embedded canine cardiac tissue were stained with hematoxylin and eosin $(a, b, c, e$, and $f ; \times 530)$ or with monoclonal antibodies directed at both canine ICAM-1 (CL18/1D8) and CD18(R15.7) and counterstained with hematoxylin and eosin $(D ; \times 1,325) .(a)$ Myocardium of an untreated (control) animal shows only rare neutrophils; red cells are present in capillaries, and sarcomeres are in regular array. $(b)$ In an animal subjected to $1 \mathrm{~h}$ ischemia and $1 \mathrm{~h}$ of reperfusion, margination of neutrophils and beginning of infiltration into the interstitium are seen in the vicinity of myocardial veins. (c) After $1 \mathrm{~h}$ of ischemia and $3 \mathrm{~h}$ of reperfusion, dense focal infiltrates of neutrophils are seen within vascular lumens and in the interstitium, adjacent to necrotic tissue. Contraction bands and increased eosinophilia are visible in the upper half of the micrograph. $(d)$ Similar findings of neutrophil infiltration in another animal subjected to $1 \mathrm{~h}$ ischemia and $3 \mathrm{~h}$ reperfusion. Numerous neutrophils (stained with anti-CD18 MAb) surround veins which stain strongly for levels of ICAM-1 (as shown by immunostaining). Findings illustrated in $c$ and $d$ are representative of those observed in ischemic tissue of four other animals studied under the same experimental conditions (i.e., $1 \mathrm{~h}$ ischemia, $3 \mathrm{~h}$ reperfusion). Focal interstitial PMN infiltrates are also commonly seen in and adjacent to zones of contraction band necrosis in animals subjected to $1 \mathrm{~h}$ of ischemia and $6 \mathrm{~h}$ of reperfusion $(e)$ or $1 \mathrm{~h}$ of ischemia and $24 \mathrm{~h}$ of reperfusion $(f)$. 

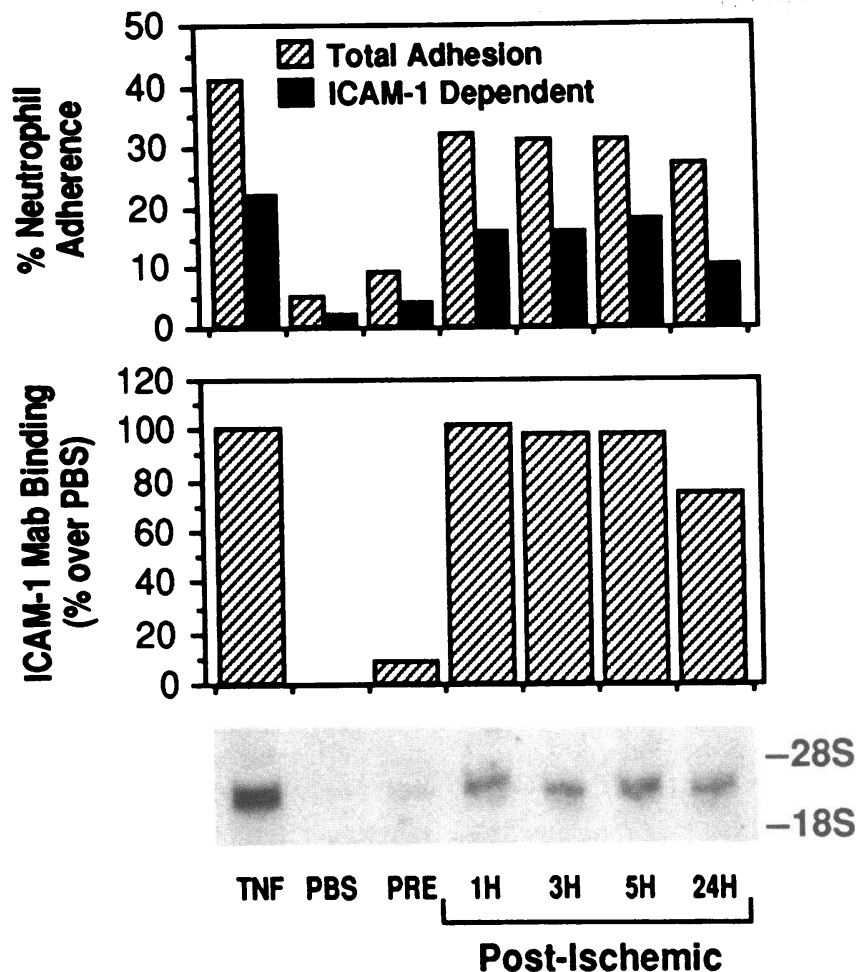

Figure 7. Induction of ICAM-1 in CJVEC by postischemic cardiac lymph. Cardiac lymph samples were obtained before coronary artery occlusion and at designated times during reperfusion. CJVEC monolayers were preincubated with a 1:7 dilution of cardiac lymph, PBS, or rTNF $\alpha(30 \mathrm{U} / \mathrm{ml})$ for $3 \mathrm{~h}$ at $37^{\circ} \mathrm{C}$. CJVEC were then used in assays of neutrophil adherence (top panel), in determinations of anti canine ICAM-1 mAb (CL18/1D8), ( $10 \mu \mathrm{g} / \mathrm{ml})$ binding to CJVEC (middle panel), and in Northern blot analyses of RNA isolated from CJVEC (bottom panel). ICAM-1-dependent adhesion as shown, represents the percentage of total adhesion inhibited by CD18/6 mAb $(10 \mu \mathrm{g} / \mathrm{ml})$. For Northern blots, $15 \mu \mathrm{g}$ of total cell RNA was loaded in each lane. Relative levels of ICAM-1 mRNA, surface protein expression, and ICAM-1-dependent neutrophil adhesion induced by postischemic lymph are demonstrated. $\bullet$, Total adhesion; $\bullet$, ICAM1-dependent adhesion.

become adhesive for neutrophils. Peak stimulatory activity for ICAM-1 mRNA in CJVEC and cardiac myocytes was evident in lymph samples collected during the immediate postreperfusion interval (Figs. 8 and 9). This finding suggests that secretion of preformed cytokines/mediators as well as biosynthesis of mediators capable of stimulating ICAM-1 may occur as a consequence of ischemia in canine myocardium. Kukielka et

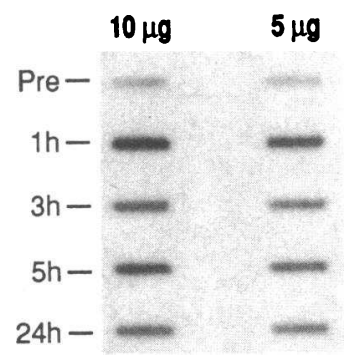

Figure 8. Induction of ICAM-1 in CJVEC by postischemic cardiac lymph. Cardiac lymph samples were obtained before coronary artery occlusion and at designated intervals after reperfusion. These were incubated with CJVEC monolayers $(3 \mathrm{~h}$, $37^{\circ} \mathrm{C}$ ) in separate $\mathrm{T}-75$ flasks. Total cell RNA was isolated and slot blots were performed and probed with ${ }^{32} \mathrm{P}$ ICAM-1 cDNA as described in Methods. Relative levels of ICAM-1 mRNA elicited by postischemic, as compared with preischemic lymph, are demonstrated.

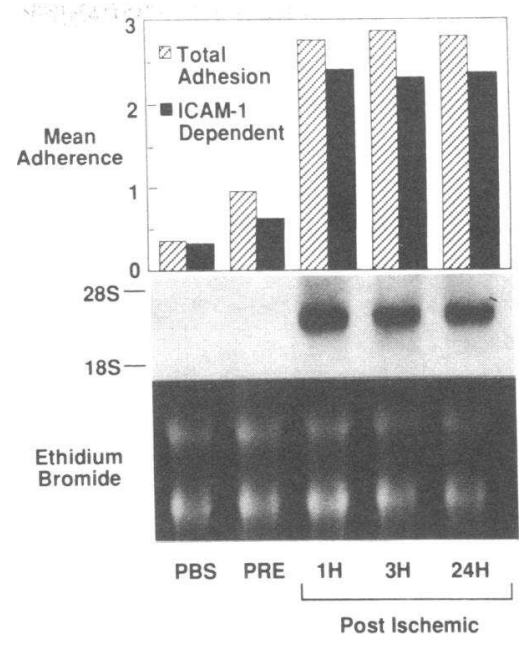

Figure 9. Induction of ICAM-1 mRNA and ICAM-1-dependent neutrophil adhesion in cardiac myocytes by postischemic cardiac lymph. Lymph samples were obtained before coronary artery occlusion and at designated times during reperfusion. Isolated myocytes were incubated with a 1:7 dilution of cardiac lymph for $3 \mathrm{~h}$ at $37^{\circ} \mathrm{C}$. Myocytes were used in assays of neutrophil adherence (top panel) in the presence or absence

of anti-ICAM-1 mAb C18/6 $(40 \mu \mathrm{g} / \mathrm{ml})$, and to prepare RNA for Northern blots probed with ${ }^{32} \mathrm{P}$ canine ICAM-1 cDNA (middle panel). $20 \mu \mathrm{g}$ of total RNA was loaded in each lane shown by ethidium bromide staining ( bottom panel). Relative levels of ICAM-1 mRNA and ICAM-1-dependent neutrophil adhesion (total adhesion-adhesion in the presence of $\mathrm{CL} 18 / 6)$ are demonstrated. $\square$, Total adhesion; $₫$, adhesion in the presence of CL18/6.

al. have shown that E-selectin is also elicited in endothelial cells in vitro by postischemic lymph with kinetics similar to ICAM1 (48). The specific cytokines responsible for these activities

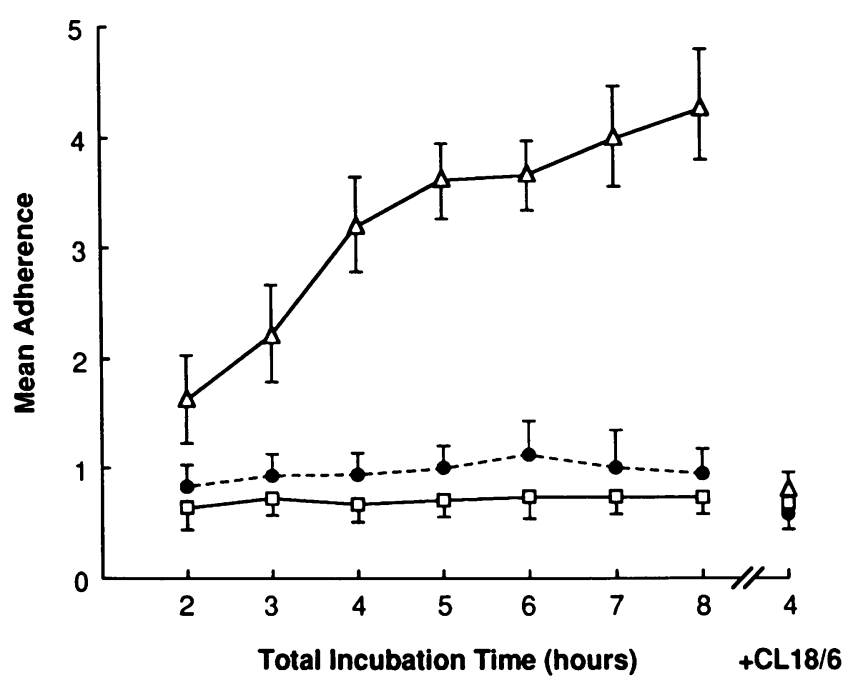

Figure 10. Stimulation of ICAM-1-dependent neutrophil adhesion in cardiac myocytes by postischemic cardiac lymph. Lymph samples were collected before or during the first hour of reperfusion after $1 \mathrm{~h}$ of ischemia. In these studies, cardiac myocytes were incubated with lymph ( $1: 7$ dilution, $\left.37^{\circ} \mathrm{C}, 30 \mathrm{~min}\right)$ and the washed (PBS, $30 \mathrm{~min}$ ). Myocyte suspensions were then incubated with neutrophils for $1 \mathrm{~h}$ either immediately after washing or after 1, 2, 3, 4, 5, or 6 additional hours of incubation (23). Adhesion was evaluated as described in Methods at the designated time intervals (total incubation interval). For mAb inhibitive studies, the anti-ICAM (mAb CL18/6 $40 \mu \mathrm{g} / \mathrm{ml}$ ) was added to myocyte suspensions $5 \mathrm{~min}$ before addition of neutrophils. As shown, postischemic but not preischemic lymph stimulates neutrophil-myocyte adhesion after all incubation intervals tested; after $4 \mathrm{~h}$ incubation essentially all stimulated adhesion is inhibited by CL18/6 mAb. $\triangle$, Postischemic cardiac lymph; $\bullet$, preischemic cardiac lymph; $\square$, PBS. 
have not been completely defined. We have previously shown that IL-6, IL-1 $\beta$, TNF $\alpha$, and endotoxin will stimulate ICAM-1 expression in isolated canine cardiac myocytes $(23,24)$ and that TNF $\alpha$ and endotoxin will stimulate ICAM-1 expression in CJVEC (24). There is now evidence for the presence of IL-6 in postischemic cardiac lymph (23), but since there is no published evidence that IL- 6 will stimulate ICAM-1 production by endothelial cells, it is likely that other cytokines are present in cardiac lymph as well.

Factors in lymph stimulating ICAM-1 expression also appear to be distinct from those shown to induce other adhesion determinants in ischemic myocardium. For example, Manning et al. have shown that stimulatory activity for P-selectin mRNA in postischemic cardiac lymph is maximal after $24 \mathrm{~h}$ of reperfusion (49). This finding is temporally inconsistent with the present studies of ICAM-1 mRNA. Thus, it appears that heterogeneous inflammatory mediators are operative as a consequence of myocardial ischemia, and that mechanisms involving differential regulation of several adhesion pathways may contribute to subsequent inflammatory events.

Based on our previous observations in vitro, it is reasonable to propose that ICAM-1 facilitates both the emigration of neutrophils in reperfused myocardium and their adherence-dependent cytotoxic behavior $(21,23,24,50)$. Constitutive levels of ICAM-1 on endothelial cells appear to be sufficient to support CD18-dependent transendothelial migration of neutrophils in response to chemotactic stimuli (27). Since we were unable to show increased ICAM-1 expression on endothelial cells in the ischemic and reperfused cardiac segments, and since Dreyer et al. $(7,19)$ have clear evidence for chemotactic activity in the extracellular fluid of ischemic and reperfused myocardium, it is possible that the constitutive ICAM-1 would play such a role in vivo. In contrast, the cytotoxic activity of neutrophils for cardiac myocytes in vitro is dependent on newly synthesized ICAM-1 expressed on the surface of the myocyte after cytokine stimulation $(34,51)$ and chemotactic upregulation of CD1 lb/ CD18 on neutrophils (52). A CD1 1b/CD18-dependent mechanism apparently augments the neutrophil's oxidative burst after chemotactic stimulation $(21,30)$. Thus, constitutive endothelial ICAM-1 may be sufficient for neutrophil emigration, and newly expressed ICAM-1 may participate in the myocardial injury associated with reperfusion only under circumstances where a leukotactic gradient and neutrophil activation are present. Presumably, the absence of a chemotactic gradient in control areas would preclude such cytotoxicity even if ICAM-1 were present. The finding that neutrophil emigration into reperfused myocardium coincides regionally with the transcription of ICAM-1 mRNA and the expression of ICAM1 (current results) and with the localization of complement components $(6,19)$ supports this hypothesis. It is likely that some myocyte ICAM-1 actually may be expressed before the 6 $h$ period required for immunostaining based on data in vitro in Fig. 10. However, a series model with a neutrophil transmigration phase preceding the expression of parenchymal ICAM-1 seems reasonable.

The use of anti-ICAM-1 mAb in experimental models of myocardial ischemia and reperfusion has resulted in reduced tissue damage, then further supporting a deleterious role for ICAM-1 in this process, at least within the initial $5 \mathrm{~h}$ after coronary artery occlusion. The $\mathrm{R} 6.5 \mathrm{mAb}(1 \mathrm{mg} / \mathrm{kg})$ was shown to attenuate myocardial necrosis in rabbits when given intravenously $15 \mathrm{~min}$ before $1 \mathrm{~h}$ of occlusion followed by $5 \mathrm{~h}$ of reperfusion (53). Preliminary studies using R6.5 mAb also demonstrated protection against myocardial necrosis in primates when provided $30 \mathrm{~min}$ before $90 \mathrm{~min}$ of coronary artery occlusion and $4 \mathrm{~h}$ of reperfusion (20). Several studies have shown protective efficacy of anti CD18 or CD1 lb monoclonal antibodies in canine $(13-15,18)$, rabbit $(53,54)$, and primate (20) models of myocardial ischemia and reperfusion. Since ICAM- 1 is a natural ligand for CD1 la/CD18 and CD11b/ CD18 subunits, these studies indirectly support the participation of ICAM-1 in myocardial injury. However, CD18-dependent neutrophil sequestration and certain CD18-dependent functions (e.g., homotypic aggregation ) contributing to inflammatory injury may involve ICAM-1 independent mechanisms (Smith, C. W., personal communication). Recent studies by Dreyer et al. (18) demonstrate increased CD18-dependent sequestration of radiolabeled canine neutrophils in ischemic canine myocardium limited to the initial $4 \mathrm{~h}$ of reperfusion. These findings are consistent with the present findings showing constitutive levels of ICAM-1 on endothelial cells, and upregulation of ICAM-1 on myocytes at later time intervals. As chemotactic activity in ischemic lymph evolves and wanes during the initial $4 \mathrm{~h}$ of reperfusion in our experimental model $(7,18$, 19 ), the pathogenic behavior of neutrophils may involve the upregulation and adhesive interactions of CD11b/CD18 with its ligand(s) on neutrophils and endothelial cells, and with newly expressed ICAM-1 on myocytes $(24,34)$.

Although intense margination and initial transmigration of neutrophils were seen at $1 \mathrm{~h}$ after reperfusion, prominent interstitial infiltrates of neutrophils were seen by $3 \mathrm{~h}$ of reperfusion of ischemic myocardial segments, comparable to those seen at later time intervals. This correlates very well with our previous work demonstrating leukotactic activity in the cardiac lymph $(7,19)$ and radiolabeled neutrophil influx (18) occurring principally in the first 3-4 h of reperfusion.

Previous reports have described an acute inflammatory reaction during the early period of myocardial reperfusion and suggest that inflammatory infiltration is seen only much later when ischemic tissue is not reperfused (55-59). Pathologic changes described in human autopsy material are consistent with the experimental findings in animals subjected to permanent ischemia without reperfusion (1). In the present studies emigrating neutrophils were consistently regionally associated with veins demonstrating strong ICAM-1 staining, further suggesting a relationship of the constitutive endothelial ICAM-1 to neutrophil transmigration.

Previous investigations in experimental animals and biopsies of human tissues document the upregulation of ICAM-1 in vivo on cells other than endothelium. In response to various inflammatory mediators, ICAM-1 can be induced not only on endothelial cells, but on a broad spectrum of mesenchymal and epithelial cell types (60-63). The kinetics of induction of ICAM-1 on cardiac myocytes as shown here are similar to those observed by Vejlsguard et al. (62) on keratinocytes of human skin after allergic contact dermatitis testing, who demonstrated induction of ICAM-1 on human keratinocytes as early as $4 \mathrm{~h}$ after application of contact patches. By $48 \mathrm{~h}$ after contact, all specimens expressed ICAM- 1 on keratinocytes concurrent with the appearance of heavy mononuclear cell dermal infiltrates and maximal clinical signs of dermatitis. Related studies in a murine model of contact dermatitis showed focal ICAM-1 expression on keratinocytes $24 \mathrm{~h}$ after dinitrofluorobenzene challenge and high levels of ICAM-1 on all keratino- 
cytes $72 \mathrm{~h}$ after challenge (64). Adams et al. reported marked induction of ICAM-1 on bile ducts, endothelium and perivenular hepatocytes of liver allografts in patients with acute or chronic rejection (63); in this setting, ICAM-1 may serve to initiate the inflammatory response of rejection and/or to determine the cellular targets for CD18-dependent immune damage by infiltrating lymphocytes and neutrophils (65). Induction of ICAM-1 on vascular or tubular cells may serve a similar role in renal allograft rejection $(66,67)$ and increased levels of ICAM-1 on lung epithelial cells elicited by Ascaris antigen in sensitized primates may facilitate the pathogenic effects of eosinophils (61).

The present study strengthens our previous suggestions regarding a potential role for ICAM-1 in inflammatory injury of the myocardium. It confirms our hypothesis that ICAM-1 is induced in ischemic myocardium. These studies indicate that the expression of ICAM-1 on tissue or parenchymal cells is possibly an important pathogenic mechanism facilitating the cytotoxic potential of neutrophils and other leukocytes.

\section{Acknowledgments}

We appreciate the continued support of Dr. Ralph D. Feigin, Chairman of the Department of Pediatrics at Baylor College of Medicine and Physician-In-Chief at Texas Children's Hospital. We acknowledge the excellent technical assistance of Peggy Jackson, Gary Liedke, Bonnie Hughes, Theresa Ty, Shirley Williams, and Jessica Zhu, as well as the expert secretarial assistance of Carol McGary and Michelle Swarthout.

This work was supported by National Institutes of Health grants HL-42550, HL-41408, AI-19031, and AI-23521, a grant from Boehringer Ingelheim Pharmaceuticals, Inc., and a grant from The Methodist Hospital Foundation (G. L. Kukielka).

\section{References}

1. Mallory, G. K., P. D. White, and J. Salcedo-Salgar. 1939. The speed of healing of myocardial infarction. A study of the pathologic anatomy in seventytwo cases. Am. Heart J. 18:647-671.

2. Mullane, K. M., and C. W. Smith. 1990. The role of leukocytes in ischemic damage, reperfusion injury and repair of the myocardium. In Pathophysiology of Severe Ischemic Myocardial Injury. H. M. Piper, editor. Kluwer Academic Publishers, Dordrecht. 239-267.

3. Mullane, K. M., N. Read, J. A. Salmon, and S. Moncada. 1984. Role of leukocytes in acute myocardial infarction in anesthesthized dogs. Relationship to myocardial salvage by anti-inflammatory drugs. J. Pharmacol. Exp. Ther. 228:510-522.

4. Engler, R. L., M. D. Dahlgren, M. A. Peterson, A. Dobbs, and G. W. Schmid-Schonbein. 1986. Accumulation of polymorphonuclear leukocytes during 3h experimental myocardial ischemia. Am. J. Physiol. 251:H93-100.

5. Schmid-Schonbein, G. W., and R. L. Engler. 1987. Granulocytes as active participants in acute myocardial ischemia and infarction. Am. J. Cardiovasc. Pathol. 1:15-30.

6. Rossen, R. D., J. L. Swain, L. H. Michael, S. Weakley, E. Giannini, and M. L. Entman. 1985. Selective accumulation of the first component of complement and leukocytes in ischemic canine heart muscle: a possible initiator of an extra myocardial mechanism of ischemic injury. Circ. Res. 57:119-130.

7. Dreyer, W. J., C. W. Smith, L. H. Michael, R. D. Rossen, B. J. Hughes, M. L. Entman, and D. C. Anderson. 1989. Canine neutrophil activation by cardiac lymph obtained during reperfusion of ischemic myocardium. Circ. Res. 65:1751-1762.

8. Engler, R. L., M. D. Dahlgren, D. D. Morris, M. A. Peterson, and G. W. Schmid-Schonbein. 1986. Role of leukocytes in response to acute myocardial ischemia and reflow in dogs. Am. J. Physiol. 251:H314-323.

9. Romson, J. L., B. G. Hook, S. L. Kunkel, G. D. Abrams, M. A. Schork, and B. R. Lucchesi. 1983. Reduction of the extent of ischemic myocardial injury by neutrophil depletion in the dog. Circulation. 67:1016-1023.

10. Jolly, S. R., W. J. Kane, B. G. Hook, G. D. Abrams, S. L. Kunkel, and B. R. Lucchesi. 1986. Reduction of myocardial infarct size by neutrophil depletion: effect of duration of occlusion. Am. Heart J. 112:682-690.

11. DeLorgeil, M., A. Basmadjian, M. Lavalle, R. Clement, D. Millette, G. Rousseau, and J. G. Latour. 1989. Influence of leukopenia on collateral flow, reperfusion flow, reflow ventricular fibrillation, and infarct size in dogs. $A m$. Heart J. 117:523-532.

12. Harlan, J. M. 1990. Consequences of leukocyte-vessel wall interactions in inflammatory and immune reactions. Semin. Thromb. Hemostasis. 13:434-444.

13. Simpson, P. J., R. F. Todd III, J. C. Fantone, J. K. Mickelson, J. D. Griffin, and B. R. Lucchesi. 1988. Reduction of experimental canine myocardial reperfusion injury by a monoclonal antibody (anti-Mol, anti-CDIlb) that inhibits leukocyte adhesion. J. Clin. Invest. 81:624-629.

14. Todd, R. F., III, P. J. Simpson, and B. R. Lucchesi. 1989. Anti-inflammatory properties of monoclonal anti-Mol (CD1 lb/CD18) antibodies in vitro and in vivo. In Leukocyte Adhesion Molecules: Structure, Function, and Regulation. T. A. Springer, D. C. Anderson, A. S. Rosenthal, and R. Rothlein, editors. Springer-Verlag, New York. 125-137.

15. Simpson, P. J., R. F. Todd III, J. K. Mickelson, J. C. Fantone, K. P. Gallagher, K. A. Lee, Y. Tamura, M. Cronin, and B. R. Lucchesi. 1990. Sustained limitation of myocardial reperfusion injury by a monoclonal antibody that alter leukocyte function. Circulation. 81:226-237.

16. Richardson, C., A. DiPaula, J. Hildreth, and L. Becker. 1989. Failure of a monoclonal antibody directed against the neutrophil adhesion complex to reduce myocardial reperfusion injury. Circulation. 80 (Suppl. II):II-401.

17. Tanaka, M., S. E. Brooks, G. P. Fitzharris, R. C. Stoler, R. B. Jennings, and K. A. Reimer. 1990. Effect of the IB4 anti-CD18 antibody on myocardial PMN accumulation and infarct size in dogs. FASEB (Fed. Am. Soc. Exp. Biol.) J. 4:A1020.

18. Dreyer, W. J., L. H. Michael, M. S. West, C. W. Smith, R. Rothlein, R. D. Rossen, D. C. Anderson, and M. L. Entman. 1991. Neutrophil accumulation in ischemic canine myocardium: insights into the time course, distribution, and mechanism of localization during early reperfusion. Circulation. 84:400-411.

19. Dreyer, W. J., L. H. Michael, R. D. Rossen, T. Nguyen, D. C. Anderson, C. W. Smith, and M. L. Entman. 1991. Evidence for C5a in post-ischemic canine cardiac lymph. Clin. Res. 39:271 A.(Abstr.)

20. Rothlein, R., R. W. Barton, and R. Winquist. 1991. The role of intercellular adhesion molecule-1 (ICAM-1) in the inflammatory response. In Cellular and Molecular Mechanisms of Inflammation. Academic Press, Inc., Orlando, FL. 171-180.

21. Entman, M. L., K. Youker, S. B. Shappell, C. Siegel, R. Rothlein, W. J. Dreyer, F. C. Schmalstieg, and C. W. Smith. 1990. Neutrophil adherence to isolated adult canine myocytes: evidence for a CD18-dependent mechanism. $J$. Clin. Invest. 85:1497-1506.

22. Smith, C. W., D. C. Anderson, A. A. Taylor, R. D. Rossen, and M. L. Entman. 1991. Leukocyte adhesion molecules and myocardial ischemia. Trends Cardiovasc. Med. 1:167-170.

23. Youker, K., C. W. Smith, D. C. Anderson, D. Miller, L. H. Michael, R. D. Rossen, and M. L. Entman. 1992. Neutrophil adherence to isolated adult cardiac myocytes: induction by cardiac lymph collected during ischemia and reperfusion. J. Clin. Invest. 89:602-609.

24. Smith, C. W., M. L. Entman, C. L. Lane, A. L. Beaudet, T. I. Ty, K. Youker, H. K. Hawkins, and D. C. Anderson. 1991. Adherence of neutrophils to canine cardiac myocytes in vitro is dependent on intercellular adhesion molecule1. J. Clin. Invest. 88:1216-1223.

25. Smith, C. W., R. Rothlein, B. J. Hughes, M. M. Mariscalco, F. C. Schmalstieg, and D. C. Anderson. 1988. Recognition of an endothelial determinant for CD18-dependent human neutrophil adherence and transendothelial migration. J. Clin. Invest. 82:1746-1756.

26. Woetman, A. A., R. S. Weening, M. N. Hamers, L. J. Meerhof, A. A. A. M. Bot, and D. Roos. 1981. Phagocytosing human neutrophils inactivate their own granular enzymes. J. Clin. Invest. 67:1541-1549.

27. Furie, M. B., M. C. A. Tancinco, and C. W. Smith. 1991. Monoclonal antibodies to leukocyte integrins $\mathrm{CD} 1 \mathrm{la} / \mathrm{CD} 18$ and $\mathrm{CD} 1 \mathrm{lb} / \mathrm{CD} 18$ or intercellular adhesion molecule-1 (ICAM-1) inhibit chemoattractant-stimulated neutrophil transendothelial migration in vitro. Blood. 78:2089-2097.

28. Anderson, D. C., R. Rothlein, S. D. Marlin, S. S. Krater, and C. W. Smith 1990. Impaired transendothelial migration by neonatal neutrophils: abnormalities of Mac-1 (CD1 lb/CD18)-dependent adherence reactions. Blood. 78:26132621.

29. Luscinskas, F. W., M. I. Cybulsky, J.-M. Kiely, C. S. Peckins, V. M. Davis, and M. A. Gimbrone. 1991. Cytokine-activated human endothelial monolayers support enhanced neutrophil transmigration via a mechanism involving both endothelial-leukocyte adhesion molecule-1 and intercellular adhesion molecule1. J. Immunol. 146:1617-1625.

30. Shappell, S. B., C. Toman, D. C. Anderson, A. A. Taylor, M. L. Entman, and C. W. Smith. 1990. Mac-1 (CD1 1b/CD18) mediates adherence-dependent hydrogen peroxide production by human and canine neutrophils. J. Immunol. 144:2702-2711.

31. Nathan, C. F. 1987. Neutrophil activation on biological surfaces: massive secretion of hydrogen peroxide in response to products of macrophages and lymphocytes. J. Clin. Invest. 80:1550-1560.

32. Nathan, C. F. 1989. Respiratory burst in adherent human neutrophils: triggering by colony-stimulating factors CSF-GM and CSF-G. Blood. 73:301306. 
33. Nathan, C. F., S. Srimal, C. Farber, E. Sanchez, L. Kabbash, A. Asch, J. Gailit, and S. D. Wright. 1989. Cytokine-induced respiratory burst of human neutrophils: dependence on extracellular matrix proteins and CD11/CD18 integrins. J. Cell Biol. 109:1341-1349.

34. Entman, M. L., K. Youker, T. Shoji, G. Kukielka, S. B. Shappell, A. A. Taylor, and C. W. Smith. 1992. Neutrophil induced oxidative injury of cardiac myocytes: a compartmented system requiring CD11b/CD18-ICAM-1 adherence. J. Clin. Invest. 90:1335-1345.

35. Rossen, R. D., L. H. Michael, A. Kagiyama, H. E. Savage, G. Hanson, J. N. Reisbery, J. N. Moake, S. H. Kim, S. Weakly, E. Giannini, and M. L. Entman. 1988. Mechanism of complement activation following coronary artery occlusion: evidence that myocardial ischemia causes release of constituents of myocardial subcellular origin which complex with the first component of complement. Circ. Res. 62:572-584.

36. Kagiyama, A., H. E. Savage, L. H. Michael, G. Hanson, M. L. Entman, and R. D. Rossen. 1989. Molecular basis of complement activation in ischemic myocardium: identification of specific molecules of mitochondrial origin that bind Clq and fix complement. Circ. Res. 64:604-615.

37. Heymann, M. A., B. D. Payne, J. I. E. Hoffman, and A. M. Rudolph 1977. Blood flow measurements with radionuclide-labeled particles. Prog. Cardiovasc. Dis. XX:55-78.

38. Goddard-Finegold, J., and L. H. Michael. 1984. Cerebral blood flow and experimental intraventricular hemorrhage. Pediatr. Res. 18:7-11.

39. Smith, C. W., S. D. Marlin, R. Rothlein, C. Toman, and D. C. Anderson. 1989. Cooperative interactions of LFA-1 and Mac-1 with intercellular adhesion molecule- 1 in facilitating adherence and transendothelial migration of human neutrophils in vitro. J. Clin. Invest. 83:2008-2017.

40. Staunton, D. E., M. L. Dustin, H. P. Erickson, and T. A. Springer. 1990 The arrangement of the immunoglobulin-like domains of ICAM-1 and the binding sites for LFA-1 and rhinovirus. Cell. 61:243-254.

41. Feinberg, A. P., and B. Vogelstein. 1983. A technique for radiolabeling DNA restriction endonuclease fragments to high specific activity. Anal. Biochem. 132:6-13.

42. Yanisck-Perron, C., J. Vieira, and J. Messing. 1985. Improved M13 phage cloning vectors and host strains: nucleotide sequences of the M13 MP18 and pUC19 vectors. Gene (Amst.). 33:103-119.

43. Chomczynski, P., and N. Sacchi. 1987. Single-step method of RNA isolation by acid guanidinium thiocyanate-phenol-chloroform extraction. Anal. Bio chem. 162:156-159.

44. Maniatis, T., E. F. Fritsch, and J. Sambrook. 1989. Molecular Cloning: A Laboratory Manual. Cold Spring Harbor Laboratory, Cold Spring Harbor, NY. $545 \mathrm{pp}$.

45. Rose, M. L., C. Page, C. Hengstenberg, and M. H. Yacoub. 1993. Identifcation of antigen presenting cells in normal and transplanted human heart: importance of endothelial cells. Hum. Immunol. 28:179-185.

46. Ballantyne, C., E. Mainolf, J. Young, N. Windsor, B. Cocanougher, C. Payton-Ross, E. Lawrence, M. Pollack, D. Anderson, and R. Rothlein. 1991 Relationship of increased levels of circulating ICAM-1 after heart transplant to rejection, HLA match, and survival. Circulation. 84:11-490.(Abstr.)

47. Pigott, R., L. Dillon, I. Hemingway, and A. Gearing. 1992. Soluble forms of E-Selectin, ICAM-1 and VCAM-1 are present in the supernatants of cytokine activated cultured endothelial cells. Biochem. Biophy. Res. Commun. 187:584589.

48. Kukielka, G. L., C. L. Lane, A. M. Manning, L. H. Michael, M. L. Entman, C. W. Smith, and D. C. Anderson. 1992. Induction of myocardial ELAM-1 by ischemia and reperfusion. FASEB (Fed. Am. Soc. Exp. Biol.) J. 6:A1060.(Abstr.)

49. Manning, A. M., G. L. Kukielka, M. Dore, H. K. Hawkins, W. E. Sanders, L. H. Michael, M. L. Entman, C. W. Smith, and D. C. Anderson. 1992. Regulation of GMP-140 mRNA in a canine model of inflammation. FASEB (Fed. Am. Soc. Exp. Biol.) J. 6:A1060.(Abstr.)

50. Youker, K., G. Kukielka, T. Shoji, A. A. Taylor, C. W. Smith, and M. L.
Entman. 1991. Direct transfer of reactive oxygen from neutrophils to cardiac myocytes at site of MAC-1-ICAM-1 adherence. Circulation. 84:II-85.(Abstr.)

51. Thomas, M. L. 1989. The leukocyte common antigen family. Annu. Rev. Immunol. 7:339-369.

52. Anderson, D. C., O. Abbassi, J. D. Fortenberry, J. M. Koenig, and C. W. Smith. 1993. Abnormalities of LECAM-1 and Mac-1-dependent neutrophil-endothelial cell adhesion in the developing host. In Structure and Function of Molecules Involved in Leukocyte Adhesion. II. P. E. Lipsky, R. Rothlein, T. K. Kishimoto, R. B. Faanes, and C. W. Smith, editors. Springer-Verlag, New York. 337 355

53. Seewaldt-Becker, E., R. Rothlein, and J. W. Dammgen. 1989. CDw18 dependent adhesion of leukocytes to endothelium and its relevance for cardiac reperfusion. In Leukocyte Adhesion Molecules: Structure, Function, and Regulation. T. A. Springer, D. C. Anderson, A. S. Rosenthal, and R. Rothlein, editors Springer-Verlag, New York. 138-148.

54. Williams, F. M., P. D. Collins, S. Nourshargh, and T. J. Williams. 1988 Suppression of 111 In-neutrophil accumulation in rabbit myocardium by MoA ischemic injury. J. Mol. Cell. Cardiol. 20:S33.

55. Sommers, H. M., and R. B. Jennings. 1964. Experimental acute myocardial infarction. Histologic and histochemical studies of early myocardial infarcts induced by temporary or permanent occlusion of a coronary artery. Lab. Invest. 13:1491-1503.

56. Smith, E. F., J. W. Egan, P. J. Bugelshi, L. M. Hillegass, and D. E. Hill 1988. Temporal relation between neutrophil accumulation and myocardial reperfusion. Am. J. Physiol. 255:H1060-H1068.

57. Tennant, R., D. M. Grayzel, F. A. Sutherland, and S. W. Stringer. 1936. Studies on experimental coronary occlusion. Chemical and anatomical changes in the myocardium after coronary ligation. Am. Heart J. 12:168-173.

58. Lodge-Patch, L. 1951. The aging of cardiac infarcts, and its influence on cardiac rupture. Br. Heart J. 13:37-42.

59. Fishbein, M. C., D. Maclean, and P. R. Maroko. 1978. The histopathologic evolution of myocardial infarction. Chest. 73:843-849.

60. Dustin, M. L., K. H. Singer, D. T. Tuck, and T. A. Springer. 1988. Adhesion of $\mathrm{T}$ lymphoblasts to epidermal kertinocytes is regulated by interferongamma and is mediated by intercellular adhesion molecule-1 (ICAM-1). J. Exp. Med. 167:1323-1340.

61. Wegner, C. D., R. H. Gundel, P. Reilly, N. Haynes, L. G. Letts, and R. Rothlein. 1990. Intercellular adhesion molecule-1 (ICAM-1) in the pathogenesis of asthma. Science (Wash. DC). 247:456-459.

62. Vejlsgaard, G. L., N. L. Hansen, E. Ralf kiaer, and R. Rothlein. 1988. Role of cellular adhesion in inflammatory cutaneous disorders. In Leukocyte Adhesion Molecules: Structure, Function, and Regulation. T. A. Springer, D. C. Anderson, A. S. Rosenthal, and R. Rothlein, editors. Springer-Verlag, New York 101-105.

63. Adams, D. H., S. G. Hubscher, J. Shaw, R. Rothlein, and J. M. Neuberger. 1989. Intercellular adhesion molecule 1 on liver allograft during rejection. Lancet. ii:1122-1125.

64. Goebeler, M., J. Gutwald, J. Roth, G. Meinardus-Hager, and C. Sorg. 1990. Expression of intercellular adhesion molecule-1 in murine allergic contact dermatitis (with 1 color plate). Int. Arch. Allergy Appl. Immunol. 93:294-299.

65. Markus, B. H., A. J. Demetris, and S. Saidman. 1988. Alloreactive T lymphocytes cultured from liver transplant biopsies: association of HLA specificity with clinicopathological findings. Clin. Transplant. 2:70-75.

66. Cosimi, A. B., C. Geoffrian, T. Anderson, D. Conti, R. Rothlein, and R. B Colvin. 1989. Immunosuppression of cynomolgus recipients of renal allografts by R6.5, a monoclonal antibody to ICAM-1. In Leukocyte Adhesion Molecules: Structure, Function, and Regulation. T. A. Springer, D. C. Anderson, A. S. Rosenthal, and R. Rothlein, editors. Springer-Verlag, New York. 274-281.

67. Cosimi, A. B., D. Conti, F. L. Delmonico, F. I. Preffer, S.-L. Wee, R. Rothlein, R. B. Faanes, and R. B. Colvin. 1990. In vivo effects of monoclonal antibody to ICAM-1 (CD54) in nonhuman primates with renal allografts. $J$. Immunol. 144:4604-4612. 